\title{
Orientalismos peninsulares en el levante andaluz. Nombres y usos de algunas plantas silvestres
}

\author{
FRANCISCO TORRES MONTES \\ Universidad de Granada
}

Entre los lingüistas y etnógrafos es bien conocida la influencia de las regiones orientales de la Península en el léxico y en el folclore, en el este o nordeste de las provincias andaluzas levantinas (Almería, Granada y Jaén, con mayor extensión en la primera, y menor, gradualmente, en las otra dos) ${ }^{1}$.

Los fitónimos de origen oriental (murcianismos, aragonesismos, catalanismos - principalmente de la variedad valenciana-, u orientalismos en general) conocidos en toda o en parte de la zona andaluza señalada, son tan numerosos que no es posible estudiarlos todos aquí; por ello en este trabajo sólo cogeremos una gavilla de plantas silvestres o asilvestradas de las que, por un lado, se estudiarán los nombres que las designan, donde se trazará la isoglosa que separa las área léxicas (la del orientalismo y la del término español general o, en su caso, del andalucismo); y, por otro, describiremos sus usos tradicionales (en la medicina doméstica, en la agricultura, en las creencias y rituales, en la dieta alimentaria, etc.) ${ }^{2}$.

1 Esta influencia ha sido motivada por el contacto o relación entre regiones vecinas, y, sobre todo, en las dos primeras provincias por las repoblaciones, tras la conquista del Reino de Granada y la posterior expulsión de los moriscos, de gentes llegadas a estas comarcas del Reino de Murcia principalmente, y, en menor medida, de valencianos, manchegos, aragoneses y mallorquines (véase Llorente Maldonado 1985: 347; Abad Merino 1998: 406-411, y la bibliografía que allí se cita). Los trabajos de tipo lingüístico donde se demuestra esta influencia léxica son ya numerosos: Salvador $(1953,1957,1960)$, Llorente Maldonado (1985), Navarro Carrasco (1986, 1988), Casado Fresnillo (1989), Martínez González (1998), Torres Montes (1989, 1993), etc.; y los de punto de vista etnográfico y, en particular, etnobotánico - aunque no todos tratan de manifestar estas relaciones- empiezan también a tener importancia, sobre todo en los últimos años: la revista de botánica jiennense Blancoana (1983 y ss.), González-Tejero $(1989,1998)$, Obón de Castro (1991), Torrres Montes (1993, 1994, 1995), Martínez Lirola (1997), etc.

2 Dejamos, por tanto, para otra ocasión el estudio de fitónimos orientales de esta zona como: ababol 'amapola' ("Papaver rhoeas"), aliaga 'aulaga' (Ulex parviflorus"), agricos ("Oxalis pes-caprae"), arto 'espino, cambrón' ("Ziziphus lotus", también el "Licium 
El material que aquí se expone ha sido recogido por un método mixto; de una parte, la encuesta directa, principalmente en las provincias de Almería y Granada; y, de otra, los estudios publicados, tanto de carácter lingüístico como de índole botánica, etnobotánica o folclórica en general, que, en cada caso, se especificarán.

\section{ALCIBARA ALZABARA ZÁBILA (Agave americana L.)}

1.1. La pita o "Agave americana", es una planta que trajeron los españoles de Méjico y que pronto se naturalizó en la zona meridional de la Península. Se compone de un cono central del que sucesivamente se desenvuelven las hojas formando una roseta; aquéllas son carnosas de un color verde claro, armadas de púas por los bordes y de una fuerte aguja en el extremo superior (punzón). Cada diez a quince años, desenvueltas todas las hojas del cogollo central de la planta, se desarrolla la inflorescencia, creciendo en pocos días un largo tallo o bohordo, que puede llegar a tener $10 \mathrm{~m}$. de altura (llamado en la zona de estudio alzabarón, zabilón, pitón y pitaco), en cuya cima produce flores de color amarillo.

Tradicionalmente en toda nuestra región, como en otros lugares de España, se plantaba para formar cercas en la tierra de labor y heredades y delimitar los bordes de los caminos ${ }^{3}$. Hoy la pita, sobre todo en las

europeum") y su fruto, artina; cardo cuco/a 'cardo corredor' ("Eryngium campestre"), collejón ("Moricondia arvensis"), crujía o clujía (Digitalis obscura", "Valantia hispida" y "Bupleurum rigidum"); espligo 'espliego', 'alhucema' ("Lavandula officinalis"), gandul ("Nicotina glauca"), que el DRAE da como centro americanismo; bierba de la sangre ("Paronychia spp."), licera 'caña gruesa y recta' ("Arundo donas L."); manrubio con la adición de la $-n$ - epentética (tanto para el "Marrubio vulgare", como para la "Ballota hirsuta Bentham."); mariselva ("Salvia lavandulifolia Vahl."); picograjo ("Roemaria hybrida"); pijo de lobo, cipote o follón de lobo (que se dan a distintas plantas parásitas del género "Orobanche spp.", a la "Cynomorium coccineum", y a la "Cistanche phelypaea (b) Coutinho"); pincho ("Salsola kali"), quebraollas o quiebraollas ("Cistus albidus", otros cistus; y "Helianthemum ssp."), rascaviejos ("Launaea arborecens (Batt.)", y "L. lanifera Paun); rompepiedras ("Herniaria cinerea" $\mathrm{y}$ "H. fontanesiin); yerba la sangre o yerba de la sangre (a varias plantas del género de las "Paronychia", utilizadas en las crisis hipertensivas); salao blanco ("Atriplex halimus L."); salao negro ("Salsola oppositifolia", "Lithora fructicosa", etc.); sisca o cisca 'carrizo' ("Saccharum ravennae (L.) Murray"), y el colectivo siscar, sisquero 'carrizal'; tuera ("Citrullus colocynthis (L.) Schrader"); varicas de san José (a varias plantas del género de "Asphodelus"); zapaticos de la Virgen, zapaticos del Señor ("Lonicera implesa Artón"; y "Lamium spp.").

3 A fines de los años cincuenta hubo, incluso, próximo al Parque Natural Cabo de Gata-Nijar (Almería), el ensayo de plantaciones de nuevas especies de ágaves impor- 
comarcas más meridionales de la zona estudiada, crece asilvestrada y de forma espontánea, de ahí que la haya incluido en este trabajo.

\subsection{Estudio lingüístico}

En las tres provincias estudiadas, como en el resto de Andalucía, la voz que domina para designar este ágave es $p^{i t a}{ }^{4}$, sólo la zona oriental de la provincia de Almería y parte de la comarca de Sierra Mágina, en Jaén, rompen esta uniformidad y, junto al término general, incorporado recientemente, se conocen otras denominaciones, la variante pitaca (fem.), que es la que se impone en todo el término de Nijar (Almería), y que no vuelvo a encontrar en otro lugar (formado sobre pitaco, siguiendo la analogía de otras plantas frutales, manzano/a, azufaifo/a); zábila (fem.), conocida en Almería desde Sierra Cabrera (términos de Sorbas y Carboneras) hasta la Cuenca Alta del río Almanzora - ya documentada para esta ágave por el botánico Rojas Clemente 1806, s. v. zabila (aunque no pone la tilde, probablemente sería esdrújula, como hoy) en la Sierra de Oria y Bayarque 5 -; y en Jaén, en parte de Sierra Mágina, en las localidades de Bedmar y Torres (Cf. Blancoana, $15-1998-6$ y 91) ${ }^{6}$. Zábila convive en la zona oriental de Almería con alzabara-alzavara y con las variantes fonéticas (todas en fem.): arcabara en Partaloa y alcibara en Vélez Rubio (Cf. Muñoz Renedo 1963: 394) ${ }^{7}$; estas últimas variantes fonéticas conectan con la región murciana (Puerto Lumbreras, Mazarrón y Lorca, has-

tadas (el henequen y el sisal) para la obtención de fibra con fines industriales, aunque pronto se abandonó por falta de interés comercial.

4 Pedro A. Alarcón ([1874] 1983: 253 y 355) cita esta planta cerca de la costa, en el límite de las provincias de Granada y de Almería: "la pita gradación anterior a la higuera chumba en el termómetro vegetal brotaba otra vez enérgicamente en las laderas de los precipiciosn.

5 Rojas Clemente, un año antes (1805: 194), dice que "en la Sierra de Oria hemos visto la Azabara, que aquí llaman zabila.

6 En la provincia de Jaén, Alcalá Venceslada (1980: $s . v$.), documenta zábila con el valor de pita, aunque no especifica términos municipales, y la acompaña con el siguiente texto: "En este camino hay muchas zábilas con pitacos altísimos". Es de las pocas voces que el autor localiza; es posible que el lexicógrafo —que era jiennensela hubiera escuchado, aunque ya estuviera en franco retroceso - como ocurre en zonas de Almería - al ser remplazada por la general pita; obsérvese que en el texto señalado, a la inflorescencia se le llama pitaco.

7 Alcalá Venceslada (1980) recoge alcibera 'hojas de pita' como voz andaluza, sin localizar. 
ta el NO. de esta región; donde se recogen para la 'pita', acibara, alcibara, alcimara, alzavara, azabara, cimbara, etc. (Cf. Sevilla 1990: s. v. alzavara; García Soriano 1932: s. v. acibara; Obón de Castro 1991: 75; Gómez Ortín 1991: s. v. azabara); y, sin solución de continuidad, por el levante peninsular, en las regiones de lengua catalana (véase el mapa n. ${ }^{\circ} 1$ ), donde atzavara se documenta en la Comunidad Valenciana y en Barcelona; adzebara en Menorca, etc., (Cf. Morales 1996: s. v. "Agave americana"); y llega al calabrés meridional donde este ágave se llama dzambara (DECLLC s. v. atzavara).

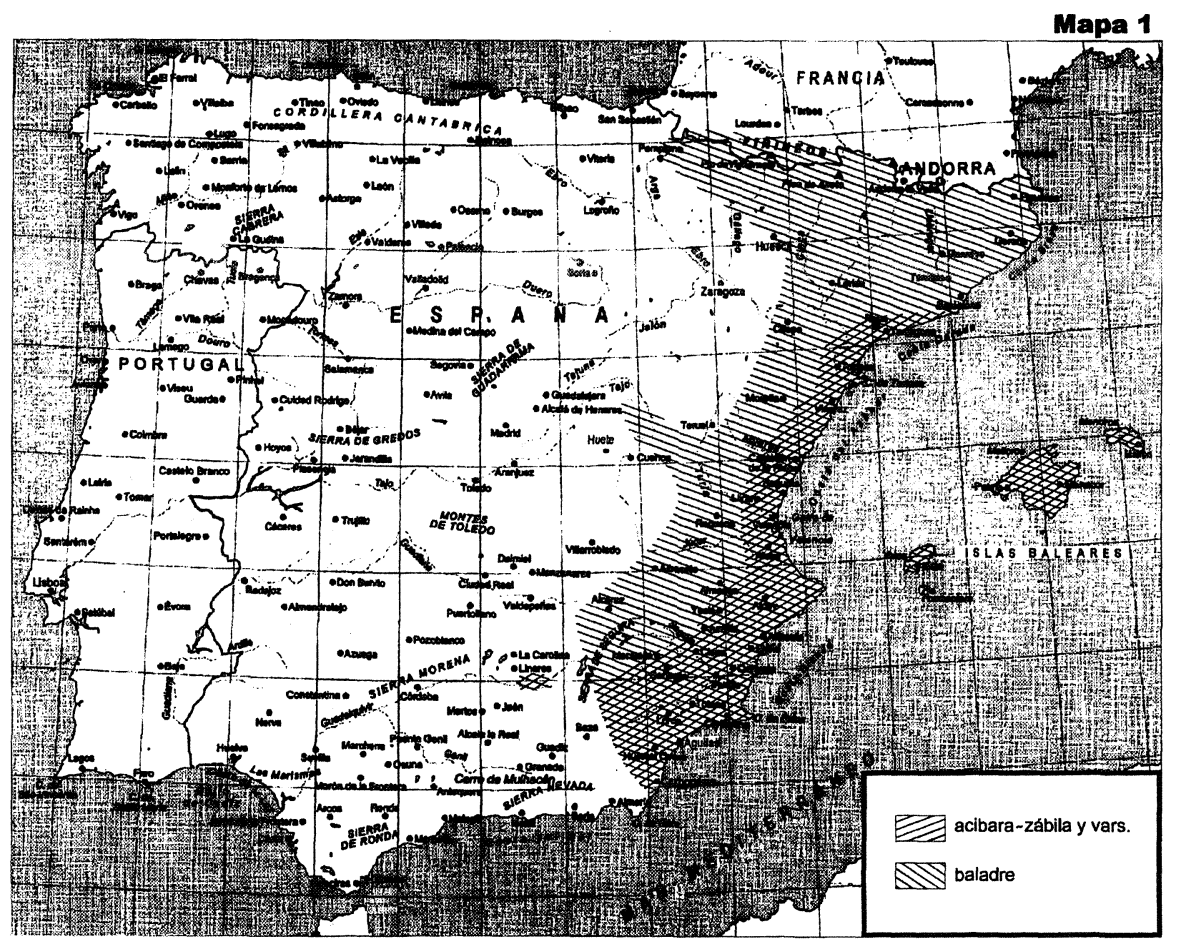

Estas denominaciones están construidas al tomar el nombre de origen árabe (azabara, acíbar(a), zábila o zabila) de otra planta, el áloe - de antigua raigambre en la Península-, con cierta analogía morfológica con el ágave (hojas grandes y carnosas con pinchos, redondeadas hacia la punta, e inflorescencia central). También se conoce el fenómeno contrario, así en las cercanías de la ciudad de Murcia, en Castellón y en Mallorca son conocidos, respectivamente, por pitera, pitera borda, y pita zábila distintos tipos de áloes (Cf. García Soriano 1932: s. v. pitera; Morales 1996: ss. $v v$. "Aloe vera", $\mathrm{y}$ "A. saponaria"). 
Para el áloe la Academia recoge los siguientes términos: acibar, acibara, azabara (que el Autoridades sólo daba para Murcia), zabida y zabila (ésta última con la acentuación esdrújula en Colombia, Perú, y Antillas; tenemos información de que también es empleada en Venezuela); todas estas formas proceden del ár. octal. sabbara 'áloe', que - según el $\mathrm{DCECH}, s . v$. zábila - por la imela en el ár. hisp. era sábbira, y, que a su vez, procede del ár. sábir (o as-sibar) 'jugo del áloe', 'acíbar'; de ahí surgieron en castellano açíbar, çauila (Cf. Nebrija 1979 [1492]: s. v. aloe; Covarrubias 1943 [1611], da entrada a sçabira y sçabila con el mismo valor) y en cat. atzavara, formas que designan la planta y, además, el jugo que de ella se extrae. Del étimo árabe más arriba señalado, surgen las dos principales variantes que hemos documentado en nuestra zona (con y sin la $a$ inicial; y en primer caso, también precedido por $a l$, por analogía con las numerosas voces que en español llevan el artículo ár.; Cf. las formas alciba, alcíbar que documenta el DHLE como sinónimos de acíbar). En el caso concreto de alzabara-alzavara, que es la voz que predomina en la zona más oriental de Almería y en comarcas de la provincia de Murcia, se ha producido - según creo- por una etim. popular desde alcibara; pues, como se ha dicho, del ágave surge en pocos días un esbelto bohordo, que la fantasía popular asimila con una 'vara'.

De esta planta, con la denominación de pita, se obtuvo muy pronto noticia en la Península; la primera documentación la da el DCECH $(s . v$. pita) en el padre Bartolomé de las Casas [1561]; para F. del Rosal [h. 1600] pita no es la planta sino una "specie de hilo"; Herrera en su Historia de las Indias (Dec. 6, lib. 3, cap. 16, apud Autoridades, s. v. pita) nos dice que de "esta hierba de Indias se obtiene un sutilissimo hilo"; y Covarrubias también recoge pita como una "yerva de Indias de la qual hazen un hilo muy delicado para guarniciones, como acá se saca el hilo del cáñamo o del lino" (1943: s. v.). Pitaco es, a su vez, un derivado de pita, que aparece por primera vez en el DRAE en la ed. de 1843; esta voz ya estaba plenamente difundida, al menos en Andalucía, a principios del XIX, Rojas Clemente, 1806, recoge pitaco en Sanlúcar (también documentado en los escritores gaditanos Fernán Caballero y el padre Coloma, véase nota 8); otras denominaciones que en Cádiz designan el bohordo de la pita son - según el citado botánico- palo de pita (Canil, Vejer), tallo de pita (Canil); en Almería recojo en la Sierra de los Filabres, hasta el límite con la provincia de Murcia, pitón (en Velefique), zabilón, alzabarón y alcibarón. El origen de pita parece ser, por todos los indicios de que disponemos, centro-americano-antillano -García de Diego, DEEH $s$. $v$, concreta un origen nahualt-; los primeros testimonios de esta planta con este nombre, vienen de esta zona. 
FRANCISCO TORRES MONTES

\subsection{Estudio etnográfico}

Alguno de los usos que tradicionalmente se le ha dado a esta planta, como es la demarcación de lindes de heredades y de caminos, hoy ha decaído en nuestra región de estudio, y sólo permanecen restos de otros tiempos. Sí se usa en todo el litoral oriental almeriense como forrajera y, en una zona más amplia, en la medicina doméstica. Como alimento de animales, sólo la comen las vacas y las cabras, troceada la zona más carnosa de la hoja, una vez que se le han quitado las púas; en cualquier caso es considerada por los ganaderos un alimento "brusco y que reseca".

En la medicina su empleo no está muy difundido, no obstante, se ha utilizado y se sigue utilizando en Andalucía Oriental. En la zona de NíjarCarboneras (Almería), uno de los sujetos me informa que se ha usado contra el reúma, dolores musculares (también en la comarca de Baza) y para curar los granos y la bronquitis infantil, aunque me advierte que el jugo de la hoja es muy fuerte; para rebajarlo se cuece en una olla con abundante agua, junto a una ristra de ajos, la parte más gruesa de la hoja de la pita picada hasta conseguir un emplasto; caliente éste se aplica con un paño en la zona dolorida. Otros usos que se han dado tradicionalmente al jugo de esta planta en las provincias de Granada y de Almería son el de antitusivo, confeccionando un jarabe; y el de vulnerario y cicatrizante, para ello el zumo de la hoja se aplica directamente en la herida, aunque no se podía abusar de este remedio - se me advierte- En Santafé (Granada) se usa para combatir las fiebres maltas. En Jaén el zumo de la hoja se ha empleado como depurativo; en Torre del Campo, Fuerte del Rey y Castillo de Locubín (Jaén) para tratar las fracturas óseas de los animales, para ello de la zona más gruesa de la hoja del ágave se cortan dos tacos rectangulares que se atan fuertemente sobre el miembro partido, y hay que esperar a que se sequen para que sane (Cf. Espantaleón 1947: 16; Blancoana, 9 -1992- 55 y 59). En Níjar el decocto de la hoja se ha empleado para combatir el piojo de las ovejas (Cf. Martínez Lirola 1997: s. v. "Agave americana").

La inflorescencia, que crece de la planta antes de morir, ha tenido múltiples usos en toda la zona suroriental de Andalucía; en la albañilería, aunque su madera no es muy resistente - "a falta de otra mejor", me dicen- se ha utilizado para formar la techumbre de cuadras, pajares, pocilgas y de las casas más humildes. Había de cortarse en octubre y secarlo a la sombra para que tuviera mayor resistencia ("así podría durar más de cincuenta añosn); también se ha utilizado para hacer escaleras. De su base, recortada con un hacha, se obtienen asientos, los posetes o 
pitacos ${ }^{8}$, que por su poca altura se han utilizado, sobre todo, para comer las migas, gachas o cualquier comida que, colectivamente, se hace directamente en la sartén o perol. En esta misma zona del litoral oriental almeriense, también de la base del tallo floral se construía, ahuecándolo por un extremo, el apartaor, es decir, el soporte de los recipientes en los que se cocina, para colocarlos cuando se retiraban del fuego, o cuando la familia comía directamente en ellos.

La fuerte punta terminal de la hoja se ha utilizado como punzón por las mujeres almerienses en las labores de bordados para hacer ojetes, y se consideraba más eficaz que los que se comerciaban en las tiendas. Otro uso tradicional en Carchalejo (Jaén) es el de servir de planta tintórea, con la pita se obtiene un tinte negro hirviendo sus hojas (Cf. Blancoana, 15 -1998-, 42). El empleo para la obtención de fibra de cordelería, uso principal y tradicional en otros lugares, aquí, sin embargo, sólo lo he podido documentar en Bedmar, donde se hacían sogas, que, por su resistencia, se empleaban para atar el arado a las caballerías (Cf. Blancoana, 15 -1998-, 6); el no usar este ágave en la cordelería, se debe a que estas funciones las ha hecho el esparto, pues, no en vano, en gran parte de nuestra zona de estudio crece la atocha, planta de la que se obtiene. En el Campo de Nijar - me informan- en los años de la posguerra hasta finales de los cincuenta, se recogía la hoja de la pita para obtener la fibra, que se exportaba fuera de la región; para ello funcionaron varias máquinas rudimentarias que trituraban la hoja, desprendían la "carne" y sacaban los hilos, que secados durante algunos días (de tres a siete), se empaquetaban para su transporte a las fábricas. De la pita, en la posguerra y en épocas de hambruna, los niños se comían la flor del tallo como golosina, y de sus hojas fabricaban carricos y otros juguetes, y, una vez secas, éstas se han aprovechado para leña.

Por último, se ha atribuido a la planta una función predictiva; cuando un verano surgían muchas inflorescencias se tenía la creencia de que el próximo año agrícola iba a ser bueno; hecho que se ha reflejado en la paremiología de la región con distintas variantes según el nombre que reciba el tallo. En el oriente de Almería y noreste de Granada, "año de pitones, año de bidones", "año de alzavarones, trigo en la era y aceite en los bidones" ${ }^{9}$ (Cf. Pardo Berbel 1987: 143) o "año de alzavarones, año de pilones" (también recojo con ese valor la frase deformada "año de pito-

8 Dos autores andaluces, Fernán Caballero (Obras Completas T. XV: 4) y L. Coloma (Cain) citan el asiento de pitaco (apud Alcalá Venceslada 1980: s. v. pitaco).

9 Igual en Murcia, "Año de alzavarones/ trigo a montones", Sevilla (1990: s.v. alzavarón). 
nes, año de pendones"); aunque otros informadores desconfían de que prediga tal augurio.

\section{BALADRE (Nerium oleander L.)}

2.1. Esta planta, cuyo nombre en el español estándar es adelfa, vive espontáneamente en suelos húmedos y freáticos, de ahí que se encuentre en los lechos secos u orillas de ríos, ramblas y barrancos. Es un arbusto que llega a tener un magnífico porte, pues supera en algunos casos los tres metros, mantiene sus hojas - lustrosas y alargadas - durante todo el año y se viste en la época de floración de vistosas flores, que en las plantas autóctonas de esta región tienen distintas tonalidades rosas.

\subsection{Estudio lingüistico}

Las provincias orientales andaluzas se encuentran divididas de norte a sur por la isoglosa que separa el catalanismo baladre (masc.) y el término esp. adelfa (fem.), con distintas variantes fonéticas. El primero se extiende de sur a norte, de mayor a menor extensión; desde Carboneras, en la costa almeriense, al NE. de Jaén ${ }^{10}$. Desde Carboneras y Sorbas, se prolonga por la provincia de Almería hacia el Norte y el oriente, siguiendo las Sierras de Cabrera y Filabres, el Valle del Almanzora hasta el límite con Murcia. Sistemáticamente es la forma recogida en el ALEA (m. 296) en todos los puntos encuestados en esta zona almeriense (Topares, Vélez Rubio, Contador, Oria, Perulera, Pulpí, Cantoria, Vera, Lubrín, Palomares, Villaricos y Gafarillos); en Cuevas de Almanzora la documenta el poeta local Martínez Álvarez de Sotomayor (para indicar el 'amargor': "lágrimas de baladre", 1973: 85; o "que se vuelve baladre", 1973: 17, passim); y en siglo pasado, Rojas Clemente (1806: $s . v$.) en las localidades de Lubrín y Bayarque, y el baladre blanco para el "Nerium oleander flore alba" en Sorbas. Fuera de Almería, el área de este orientalismo en Andalucía es mucho menor; en Granada en la franja nororiental (en Puebla de don Fadrique, Huéscar, Castril, Galera y Cúllar-Baza) que conecta con la zona de Almería señalada; y en la provincia de Jaén sólo lo encuentro en la comarca de Jódar (ALEA, II, m. 296). La

10 Casado Fresnillo (1988: $₫$ 8.1.5) basándose en los datos del ALEA, II, m. 296, incluye el término de Níjar en el área de baladre, sin embargo ésta se inicia, como se ha dicho, más al Este, en Carboneras y Sorbas. Rojas Clemente (1806: s. v. baladre) documenta esta voz, por error, en Cabo de Gata y Níjar. 
variante fonética del esp. estándar abelfa (también he documentado minoritariamente la forma con confusión de líquidas aberfa) es la forma dominante en las tres provincias orientales andaluzas, a excepción de la franja más oriental que, como ya se ha dicho, tiene el término baladre.

Esta planta ha dado origen, en la provincia de Almería, a microtopónimos con las dos formas léxicas según la zona; por un lado, el caserío Las Abelfas, en Gérgal (en la zona central de esta provincia); y, por otro, Baladral, un pequeño arroyo que desemboca en la Rambla de Mecenas, entre Carboneras y Mojácar; y Valadral, un estanque en Huércal Overa, en el límite con la provincia de Murcia (donde también aparece este topónimo en el término de Totana) ${ }^{11}$.

Aunque baladre, como sinónimo de adelfa, lo recoge el DRAE como voz general ${ }^{12}$, es, en realidad, un orientalismo, como muy bien vio Casado Fresnillo en Almería (1989: 260). Es la forma conocida en la provincia de Murcia (García Soriano 1932; y Gómez Ortín 1991: s. v.), en Alicante (Orihuela; Cf. Guillén García 1974: s. v.); también está documentada en Albacete (Quilis 1960: 418); Cuenca (Pizarro s. a.: s. v.); en todo el dominio catalán ${ }^{13}$, y en Aragón (Cf. ALEANR, L. 346, adición a ortiga, Llorente Maldonado 1985: 371), donde su aparición es más frecuente en los territorios más próximos al dominio lingüístico catalán (en un sólo punto en Zaragoza, frente a siete en Huesca y tres en Teruel). No obstante, el DCELLC ( $s . v$. baladre) señala una zona más amplia, y documenta su presencia en la Navarra de dominio vasco (véase su extensión en la Península en el mapa n. ${ }^{\circ} 1$ ), también en el aranés, y al otro lado de los Pirineos, en hablas del gascón (bearnés); incluso aparece belagre en Honduras, aunque aquí designa un tipo de liana.

11 La denominación oriental del Nerium ha dado origen a diversos topónimos menores en la Península: estos nombres propios nos dan información de que en esa zona crece o ha crecido espontáneamente esta planta y, además, por donde se ha extendido esta voz: en Albacete, en el término de Hellín, Baladre designa el nombre de una sierra (Madoz 1845: s. v.); en la zona de habla no catalana de Valencia aparece Fuente Baladre; y en el Pirineo catalán, Baladredo (Peñarroja Torrejón 1990: 226, n.).

12 Otros sinónimos que el DRAE da para esta planta son ojaranzo (s. $v$. 2), rodafne $\left(s . v\right.$. rodadafne, $\left.1^{\mathrm{a}}\right)$, y en Cuba rosa francesa $(s . v$. rosa). El DEA, $s . v$, tampoco señala una procedencia regional; aunque el texto que acompaña en la documentación de la voz es catalán.

13 Esta voz, en las tierras de lengua catalana, designa tres géneros diferentes, que tienen de común el ser venenosos: el Nerium, sobre todo, en la Comunidad Valenciana, que es el que aquí estudiamos; el Helleborus, y el Veratrum (Cf. DECLLC: $s$. $v$. baladre, Escrig 1871: s. v. baladre y baladral). 
El lat. VERATrum 'heléboro' ha dado en catalán baladre (Cf. DECLLC, s. v.), de donde se ha extendido por los territorios señalados. A esta forma se llega, desde el étimo latino, por la confusión de líquidas y asimilación de la vocal protónica ${ }^{14}$. El cambio de referente, de 'heléboro' a 'adelfa', se debe al carácter venenoso de las dos plantas. Derivados de esta forma lat. se encuentran también en provenzal y en italiano para designar varias plantas venenosas.

\subsection{Estudio etnográfico}

La adelfa, planta muy familiar de las culturas mediterráneas, ha estado presente en sus usos y creencias desde la más remota antigüedad. En la zona oriental de la provincia de Almería y en la franja limítrofe de la de Murcia, sus ramas tiernas se han utilizado tradicionalmente como insecticida, colocándolas sobre los cereales en los graneros (los trojes) y sobre las patatas cuando se almacenan para ir consumiéndolas a lo largo del año ${ }^{15}$. De sus troncos se hacían cayaicos 'cayados'; y sus ramas se utilizaban por los gitanos para hacer canastas y para confeccionar asientos de los sillones. En el Campo de Nijar las ramas floridas se han uilizado en las fiestas de los caseríos para hacer guirnaldas y colocarlas en los postes de la calle principal.

Respecto de su carácter venenoso no hay unanimidad de criterio entre los encuestados; pues algunos - los menos- lo desconocen; otros dicen que es venenosa para unos animales pero no para otros, como el camello y el dromedario ${ }^{16}$; y un tercer grupo, el más numeroso, señala

14 Lo extraño es la aparición, ya desde los primeros textos, del fonema inicial /b/ en vez de la etimológica /v/ — que el DECLLC, loc. cit., documenta en cat. a principios del siglo XIV-. En esta lengua aparece en R. Martí (s. XIII) su equivalencia con la voz de origen ár.: "dafla, herba quae dicitur baladre".

15 Cf. Obón de Castro (1991: 75) que documenta en Puerto Lumbreras (Murcia) el uso de las ramas y hojas de la adelfa en los sembrados de cereales para prevenir las epidemias.

16 La distinta actuación de la adelfa según el tipo de animal, ha sido una creencia que se remonta a la antigüedad; así Apuleyo en Asno de Oro -documenta Covarrubias ([1611] 1943: s. v.) — nos dice que cuando el asno buscaba la rosa, topó con la adelfa y se propuso comer sus flores, mas, al ser tan gran herbolario, reconoció que era el nerium, veneno específico para los asnos, y se abstuvo de comerlo; Plinio (1877: lib. XXIV, cap. 2) dice que las hojas de esta planta son muy venenosas para los cuadrúpedos; el Dr. Laguna, a mediados del siglo xvi [1555], advierte que "las hojas e sus flores son veneno mortífero de los perros, de los asnos, de los mulos y de otros muchos animales cuadrípedos" (1968: lib. III, cap. 83), y Covarrubias, loc. cit., repite lo dicho por Laguna. 
que es muy venenosa en general, sólo pasar por debajo de ella puede producir calvicie; y su olor causa malestar y fuertes dolores de cabeza; no obstante, en la comarca del Almanzora, en Almería, existe la creencia de que, excepcionalmente, la noche de San Juan pierde su carácter venenoso (Cf. García Ramos 1987: s. v. baladre). La opinión generalizada en nuestra región es que los animales nunca la comen; sólo un sujeto me informó de que si en alguna ocasión alguna oveja lleva muchas horas sin haber comido, por ir el rebaño de verea - es decir, de trashumancia en busca de pastos-y muerde las hojas del Nerium, en este caso irremediablemente muere. En la Sierra de Andújar (Jaén), se han utilizado sus ramas para emponzoñar las aguas de los remansos de los ríos y luego poder pescar los peces (Blancoana, 4 -1992- 52). Debido a este carácter tóxico, el pueblo ha acuñado la frase "es más malo que el baladre" para indicar que una persona o una situación son perversas, expresión que se dice en toda la Cuenca del Almanzora y en la zona más oriental de Almería, continúa en la provincia de Murcia y llega a Albacete.

Sobre lo que sí hay unanimidad es acerca del amargor de esta planta ("amarga un disparate" me dice uno de los encuestados, a pesar de que no lo haya probado; es una información que se transmite de generación a generación). De ahí que, del contraste entre su porte y belleza cuando está en flor y sus hechos, haya surgido una seguidilla que se cantaba en el Campo de Nijar por los enamorados despechados: "Eres como la abelfa,/ mala gitana,/ que echa la flor bonita/ y luego amarga/n ${ }^{17}$. El 'amargor' de la adelfa ha sido recurrente en la literatura popular, en la paremiología e, incluso, en la literatura culta. El Dr. Laguna (1968 [1555]: 431) nos informa: "y ansí, causa de su notable amargor, solemos meritoriamente rogar a Dios que a la hembra desamorada al Adelpha le sepa el aguan.

En la medicina popular de Almería he recogido su empleo como antiverricosa, para lo cual se aplica "la leche" (el látex) de la hoja sobre la verruga, después de varias aplicaciones desaparece ésta. Se ha usado también para expulsar las sanguijuelas de los animales, pero no me han sabido indicar cómo se utilizaba. En la comarca de Cabo de Gata-Nijar se emplea como callicida, para combatir el dolor de muelas y para curar ciertas heridas, para lo que se prepara un ungüento al freír en aceite de oliva y cera varios tallos jóvenes de adelfa (Martínez Lirola 1997: 230). En

17 Cantarcillo que también recoge Covarrubias en su Tesoro (s. v. adelfa). Cervantes en el Quijote (I, cap. 13) cita esta planta como adorno que se ponían los pastores y, entre sus cualidades, destaca su amargor: "cuando al cruzar una senda vieron venir hacia ellos seis pastores vestidos con pellicos negros, y coronadas las cabezas con guirnaldas de ciprés y de amarga adelfa" (el subrayado es mío). 
la provincia de Granada se han usado sus hojas en polvo como purgante, vermífugas y estornutarias (Serrano 1932: 465), y en la de Jaén he encontrado documentado su uso para los problemas cardiacos, tomada en infusión, y en veterinaria se emplean las tiras de la corteza de la ramas para coser los cabritos y corderos después de castrados (Blacoana, 4 -1992 - 52). El uso curativo de la adelfa es tradicional en la medicina, sobre todo como antídoto contra mordeduras de serpientes venenosas, ya indicado por Plinio ("homini vero contra serpentes praesidium", 1877: lib. 24, cap. 2), que luego recoge el Dr. Laguna: "Bevidas [las flores] con vino son remedio a los hombres contra las mordeduras de fieras: principalmente si se mezcla con ellas rudan; en este caso es un remedio propuesto por Dioscórides, que también nos dice que puede ser "aplicada por de fuera esta planta [y] resuelve los apostemas" (Laguna 1968: 429).

En nuestros días se ha seguido empleando este vegetal como contraveneno de las picaduras de escorpiones y alimañas en Castellón (Mulet 1987 , s. v. Baladre); otros usos medicinales los encuentro en Cuenca, donde se emplea el polvo de las hojas secas y trituradas con manteca o vaselina para curar la sarna del ganado (Pizarro s. a.: 199), el mismo uso se ha dado en el Pirineo aragonés y en Castellón (Cf. Villar Pérez 1987: 264; Mulet, loc. cit.); también en Cuenca se usa para hacer veneno contra las alimañas ${ }^{18}$ (Pizarro, loc. cit.).

\section{3. ВоJA (Artemisia spp., Santolina spp., y Salsola spp.)}

3.1. Son varias las plantas a las que alude el sust. boja (fem.), y distintas las especificaciones que se añaden a este término genérico para distinguir, principalmente, varias artemisias. En general, todas ellas son leñosas y, además, tienen en común su escaso porte (la mayor no alcanza $60 \mathrm{~cm}$.), forma redondeada, de hoja diminuta, y crece formando matorrrales en terrenos yermos y secos. En el caso de las artemisias son olorosas y están provistas de unos menudos pelos que le dan distintas coloraciones, desde blanco-grisáceo a verde oscuro.

Las denominaciones que he recogido en el oriente andaluz, en particular, en las provincias de Almería y Granada - junto al término bojason las de la oposición boja blanca ("Artemisia campestris L.", "A. Barrilieri

18 Como veneno, en este caso para matar personas, se utilizó en Argelia en la guerra de independencia contra los franceses (García Rollán 1986: 31), y en el Sáhara occidental, donde también se ha empleado como abortivo y para combatir la sarna de los animales y la caída del cabello (Bellakhdar 1978: $s . v$. Nerium). 
Besser", y "A. herba-alba Asso", y, además, en la terminología de Rojas Clemente 1805: s. $v$. "Santolina stoechas") y boja negra ("A. Barrilieri", "A. campestris", y "Salsola ginestoides"); boja entina o bojantina ("A. herbaalba", y "A. Barrilieri"), boja pulguera ("A. Barrilieri" y "A. Piretrina"), y boja yesquera ("A. herba-alba", y "A. Barrelieri"); sólo en la provincia de Almería documento boja barrillera ("Salsola oppositifolia") en el litoral oriental, y boja follonera ("A. Barrilieri") en la Cuenca del Almanzora; y en la costa granadina, boja marina para "Thimelaea hirsuta".

\subsection{Estudio lingüístico}

El término boja lo recoge el DRAE con el significado de 'abrótano' y lo da como general (lo mismo hace el DEA que sigue las sinonimias de Font Quer 1989: 799); sin embargo, el dominio de esta voz, con variantes fonéticas, está extendido por las regiones orientales peninsulares. La forma en catalán es botja y en alto aragonés bocha.

La palabra boja, sin poder precisar la planta que designa - aunque posiblemente debe de ser una artemisia-, la encuentro en diferentes textos que hacen referencias a plantas silvestres de la provincia de Almería; el primero, cronológicamente, pertenece al Diccionario de Tomás López (1986: 90) en el que el párroco de Padules (en la Alpujarra almeriense), a fines del XVIII [1795], informa de que "[el monte] está poblado de romero, mejorana, tomillo, aljedreas, retamas, arlos, gualdas, espinas, lentiscos, matapollos, toroviscos, y otras que llaman estepa, boja y jaguarzosn; otro testimonio pertenece al botánico Rojas Clemente, que tanto en 1805 como en 1806, recoge distintos tipos de bojas que veremos más abajo, en la comarca de Huéscar en Granada y en la provincia de Almería; también el Diccionario geográfico de Madoz (1845), en el artículo correspondiente a Alhama la Seca (Almería) dice que su término tiene "200 [fanegas] incultivables por ser riscos que producen atocha, romero, boja". El término boja, como ya se ha dicho, designa diferentes plantas del mismo género - y aun de distinto- con porte semejante (Cf. en catalán "botja: nom genèric per anomener les mates petites", Griera 1935-1947: s. v. botja).

La isoglosa que marca el límite de esta área léxica en Andalucía se inicia en la zona más occidental de Sierra Nevada y la Alpujarra ${ }^{19}$ (véase el mapa n. ${ }^{\circ}$ ), comprende gran parte de la provincia de Almería y enla-

19 En la Sierra de Gádor, en la Alpujarra Baja, recojo boja pulguera; y en la costa occidental almeriense, en el término de Roquetas, existe el topónimo menor El Bojar (Cf. Rueda Casinello 1983: s. v. boja). 
za con la de Granada por Huéneja y el Marquesado del Cenete hasta las comarcas nororientales (Baza), llega a Huéscar y se interna en la provincia de Jaén por la Sierra de Segura (Santiago de la Espada); el farmacéutico Espantaleón (1947: 78), enumerando las plantas medicinales de esta provincia, para la "Santolina chamaecyparissus" recoge, además de abrótano hembra y cipresillo, el término bojeta, cuya correspondencia ya daba Colmeiro; aunque posiblemente aluda a la sinonimia general de los nombres vulgares conocidos por el autor para esta planta. El área de boja enlaza por oriente, de norte a sur, con la comunidad murciana y con Albacete (donde boja es, además de distintas artemisias, 'la hojarasca del pino', Cf. Zamora Vicente 1943: 241), continúa por el levante, en la Comunidad Valenciana, en la que junto al nombre castellanizado boja (Escrig 1871: s. v. boja 'ábrótano' y bojar 'lugar poblado de bojas'), aparecen los cats. botja y botjeta, documentados principalmente en Castellón (Mulet 1987: $86-87,108$ y 124), continúa por el sur de la provincia de Tarragona, que es el límite septentrional en este dominio lingüistico. Se encuentra esta voz también en Aragón, donde aparece como bocha, y tiene extraordinaria presencia en los altos valles pirenaicos (Ferrández 1993: s. v.), precisamente allí donde mejor se guardan los restos del antiguo dialecto.

Son numerosos los adjetivos o adyacentes que acompañan al término boja para especificar las distintas plantas que recoge este sustantivo. En primer lugar recogemos la dicotomía boja blanca y boja negra, que distingue las plantas según la tonalidad blanca (también verde-grisácea) o verde oscura de sus tallos, hojas y del tomento de este vegetal, aunque, a veces, una misma planta, la "Artemisia campestris", según la zona, puede recibir ambas denominaciones. Esta oposición tiene un área muy extensa; es muy viva en Almería (ya recogida por Rojas Clemente 1806: $s$. $v$, y 1808: 181, 197, 203, passim) desde la Sierra de Alhamilla, en esta provincia, hasta el límite oriental; y en la comarcas de Huéscar y Baza en Granada; continúa por Murcia (Gómez Ortín 1991: ss. vv. boja, boja blanca, y Obón de Castro 1991: 19 y 77), en la Sierra de Segura albaceteña (Verde 1998: 251); y en Castellón sólo encuentro botja blanca para "A. campestris" (Mulet 1987: 108; y Morales 1996: 19). Otro sintagma, también muy activo en la franja más oriental de la provincia de Almería, que se une a la comarca granadina bastetana para designar, principalmente, a la "A. herba-alba", es el de boja yesquera, cuyo adyacente proviene del uso de mecha, que tradicionalmente se ha dado a esta planta (Rojas Clemente 1806: s. v., la localiza en Albox y Almería; Pardo Berbel 1987: 73; Colmeiro en Albox -1885: III, 216- para la "A. herba-alba"; Salvador 1958: s. v., en Cúllar-Baza); pero en Benamaurel recojo, para esta planta, el genérico boja. Otras expresiones, que sólo he documentado en Almería, son boja 
barrillera para la "Salsola ginestoides", recogido en el Campo de Níjar, cuyo adyacente anuncia el género al que pertenece la planta, el de las barrillas; y boja follonera en Huércal-Overa (Ceballos Jiménez 1986, s. v. "A. Barrilierin), donde el adjetivo, posiblemente, esté motivado por las explosiones sordas que produce esta planta cuando se usa como combustible. Se conoce, además, la "Thymalaea hirsuta (L.) Endl." con distintos nombres, boja marina (Serrano 1932: 453) en la costa de Granada y bojalaga en Cabo de Gata-Níjar (Almería), aunque, en realidad, este último nombre es una contaminación de bufalaga por boja (Torres Montes 1994: 504-505).

Por último, recojo la denominación boja entina (la var. bojantina en la vertiente sur de Sierra Alhamilla, Torres Montes 1994: 506-507) para las "A. herba-alba" (Colmeiro 1885: III, 216, la documenta en Almería) y la "A. Barrilieri", cuya denominación se extiende desde Almería, el Cabo de Gata-Sierra Alhamilla-Sierra de los Filabres hasta la provincia de Murcia, y se interna en la de Granada por la comarca de Baza y más al norte llega a Huéscar (Cf. Rojas Clemente 1806: s. v.; 1805: 197; González-Tejero 1989: s. $v$.). El segundo elemento de este compuesto es una variante de ontina (antina-untina), voz también de origen oriental, que para designar distintas artemisias y santolinas la encuentro en territorio aragonés y navarro (ALEANR, m. 292), donde ontina (que también se encuentra en Cuenca) y untina alternan con bocha o boxa, entre otras, para designar la "Artemisia herba-alba" en Huesca (Ferrández 1993: 223; Morales 1996: 19) ${ }^{20}$; también para una artemisia aparece en Villena (Alicante). La forma absolutamente dominante en el dominio cat. es antina, donde designa principalmente una 'planta marina' o 'un tipo de alga', también una 'roca de la costa con algas', y 'mata' de la costa en Sueca (DECLLC: $s$. $v$. antina). Esta voz se extiende por el Mediterráneo peninsular (desde el Cabo de Creus, en Gerona, hasta las proximidades de Adra en la provincia de Almería, donde aparece el topónimo Punta Entinas en el término de El Ejido); y por el Norte llega a Navarra ${ }^{21}$.

El sustantivo boja es un orientalismo, que, como tantos otros se incorpora, probablemente, en Andalucía Oriental a través de la región murciana. Corominas (DECLLC: s. v. botja) emparenta el cat. botja con el gascón

20 Sin embargo, Andolz (1984, s. v. ontina) la hace sinónimo de 'maíz'; en la costa murciana entina es una planta submarina (García Soriano 1932: s. v.).

21 Respecto del origen de esta voz, la propuesta del DCECH: $s$. $v$. ontina, es una base proto-vasco, *ONTO (Cf. ondo en el vasco actual 'planta') más un sufijo; sin embargo, Corominas rectifica en el DECLLC: $s$. $v$., y propone una nueva etimología un der. del lat. ALTUS 'alto'; a mi parecer menos convincente desde el punto de vista fonético y semántico. 
moderno pódja 'terreno yermo, que queda sin labrar', y enlaza, a su vez, ambos con el vasco *ipu, ipu-lar 'id.', con lo que le lleva a reconstruir un hipotético *IPUDI-CA, derivado del vasco-aquitano; del cual - tras la aféresis- vendrían la voz botja y las vars. bocha y boja. El citado investigador sostiene que se trata de un préstamo del cat. en tierras orientales del dominio español. Creo, no obstante, que por la extensión de este término y las variantes que presenta, no habría que descartar una base prerromana común al dominio mediterráneo y tierras orientales de la Península.

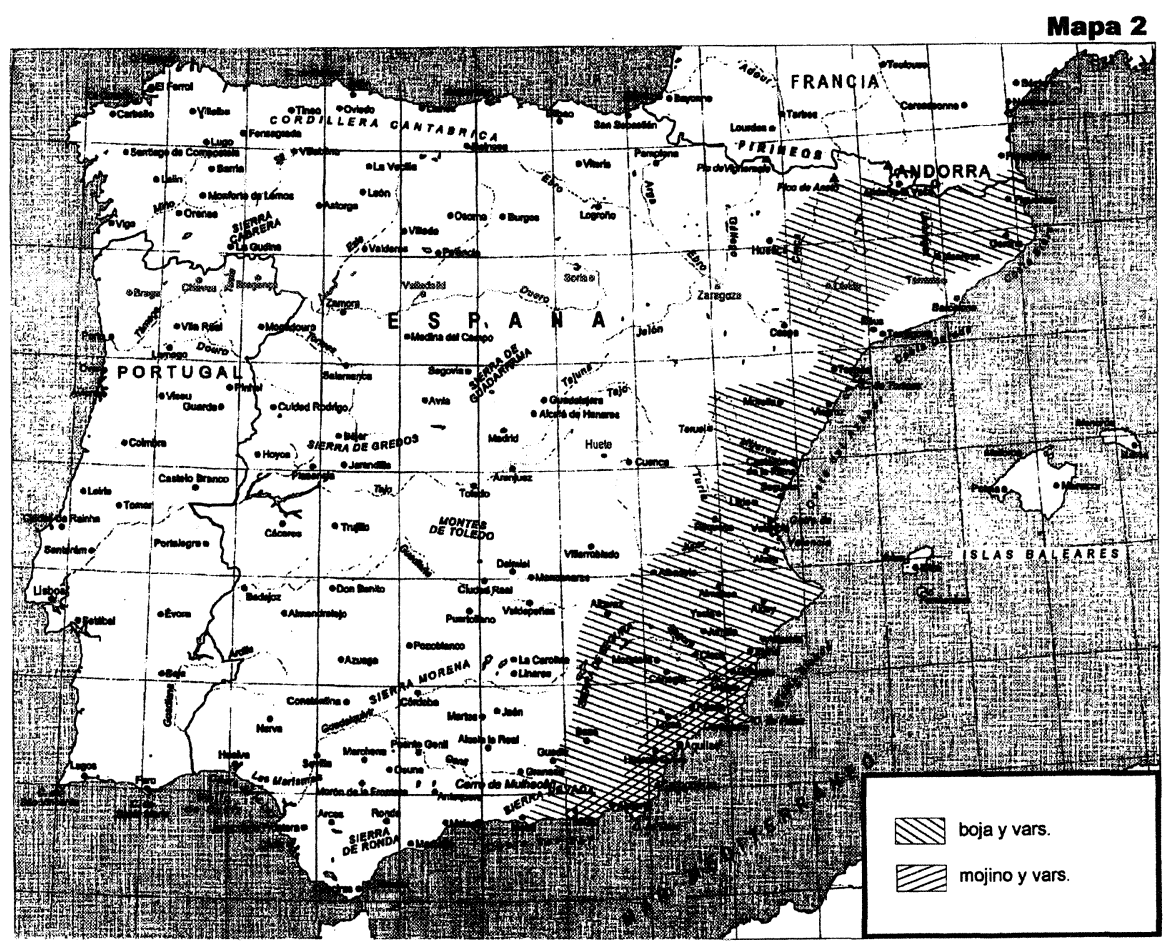

\subsection{Estudio etnográfico}

Estas matas no tienen ningún aprecio y escaso uso entre los labradores y pastores (Cf. Torres Montes 1994: 506); es más, decir que una tierra sólo cría bojas es sinónimo de terreno yermo y de muy poco valor. No obstante, he recogido algunos usos de algunas de estas plantas: todas se han utilizado, tradicionalmente, como combustible flojo, tanto en el hogar como en el horno cuando se caldeaba para hacer pan; sirven, en gene- 
ral, de pasto para el ganado lanar y caprino, y los pastores las han utilizado, mezcladas con el albardín, para hacer la cama del ganado; aunque me advierten que el estiércol que se obtiene es de poca calidad. Por otro lado, el tomento algodonoso que tienen algunas de estas plantas compuestas, se empleó como mecha o yesca, de ahí que, en casos, reciban, también el adyacente yesquera tanto en Almería como en la comarca de Baza (Cf. Salvador 1958: s. v. boja yesquera).

En la medicina doméstica, se han empleado algunas de estas artemisias; la "A. herba-alba" se utiliza en la provincia de Granada, como tónico capilar en Güejar Sierra y contra las afecciones renales en Baza y Yegen (Cf. González-Tejero 1989: s. v. "A. herba-alba"); en la de Almería, en la Cuenca del Almanzora, para resolver problemas odontológicos, para ello se hacen enjuagues de boca con el decocto de la planta, y a los pocos días - aseguran - la muela picada se cae a pedazos (Cf. García Ramos 1988: s. v. boja blanca), uso que se da en la Sierra de Segura albacetense con otras bojas (Verde 1989: 209) y en distintos lugares de la provincia de Murcia (Obón de Castro 1991: 19). La "A. Barrilieri" se coloca en las fracturas de los animales entre las tablillas y el miembro fracturado para que suelde antes, y también se emplea como antiverricosa en el Campo de Nijar (Almería), para este último remedio se aplica un rito mágicosuperticioso, el afectado por la(s) verruga(s) deberá visitar previamente al curandero, que se quedará con su nombre, y esperar al día de San Juan en el que a primera hora se dirigirá a una bojantina, que previamente habrá seleccionado, y armado de un vara o una caña golpeará contundentemente la planta; las verrugas desaparecerán cuando ésta se seque ${ }^{22}$. Otros usos curativos, en este caso junto con las santolinas, son contra los dolores de vientre, como antiséptico, y contra las afecciones estomacales, para cuyo remedio, aunque en ocasiones se ha utilizado la parte aérea en infusiones, el empleo más extendido es el de carácter mágico; se hace una cruz con dos trozos del tallo sobre el vientre del afectado, o simplemente se coloca debajo del cinturón (Cf. Torres Montes 1994: 506); estos rituales están extendidos por el oriente almeriense, por la provincia de Murcia (Obón de Castro 1991: 19 y 77) y llegan a Castellón (Mulet 1887: s. $v$. botja) y Huesca (Fernández 1993: $s$. $v$. bocha) ${ }^{23}$; también se emplea

22 Son varias las plantas que tradicionalmente se han utilizado para combatir las verrugas; véase infra: matapollo $\$ 5.3$; en la Cuenca del Almanzora también se utiliza el enebro, para lo que a la vez que se van cortando ramas se dice la siguiente cancioncilla con el nombre del afectado: “Enebro, enebroso/ quítale las verrugas / a [...] / el verrugoso" (Pardo Berbel 1987: 75).

23 En Aragón la bocha o sus ramas se ponían "a los gusanos de seda para que suban a elaborar el capel ['capullo del gusano de seda']. ( Pardo Asso 1938: s. v., el 
en Lanjarón como tónico capilar, y contra las afecciones renales en Baza y Caniles -Granada- (González Tejero 1989: s. v.). Rojas Clemente (1805: 203) documenta que en Oria (Almería) se utilizaba la boja negra ("A. campestri"), en el pasado siglo, para teñir "de pagizo las colchas", famosas por su calidad en esa época en distintas regiones españolas; hoy en esta localidad y en parte de la Cuenca Alta y Media del Almanzora se emplea esta planta para combatir los dolores intestinales de los niños, para lo cual se coloca un tallo entre la ropa y el vientre (Cf. García Ramos 1988: s. $v$. boja negra).

En el caso de la "Salsola ginestoides", como otras barrillas, ésta se ha venido utilizando en el litoral almeriense hasta los años de la posguerra, casi exclusivamente, para elaborar jabón.

\section{MATAMOSQUERA OLIVARDA (Dittrichia viscosa (L.) Grenter)}

4.1. La "Dittrichia viscosa" (antes "Inula viscosa L.") es una planta de base leñosa y tallos rectos de olor a resina, toda ella tiene, sobre todo en verano, una sustancia pegajosa-viscosa, de ahí el calificativo del nombre científico y de algunos de sus nombres vulgares; se caracteriza, además, por sus flores amarillas en cabezas terminales; se cría en lugares incultos, orillas de caminos, ribazos, etc.; es muy abundante en toda la región. En la Andalucía Oriental recibe distintos nombres - todos fems.- altabaca y vrs., matamosquera y vars., pegajosa, y olivarda, que es el nombre que recoge el DRAE como voz general

\subsection{Estudio lingüistico}

Una vez más, el botánico Rojas Clemente (1806) nos da información del modo de designar esta ínula en Andalucía, y divide el Reino de Granada en dos partes: una, la zona occidental que conecta con el Reino de Sevilla, tiene el arabismo altabaca ${ }^{24}$; la otra, la oriental, el romance olivarda, que es la forma mayoritariamente utilizada en toda la franja central de las provincias de Almería y Granada y en la mayor parte de la

DRAE - s. $v$. embojo, $2 .^{2}$ ac. - da el mismo significado como general: "conjunto de ramas, por lo general de boja, que se pone a los gusanos de seda para que hilen").

24 El DEA, siguiendo a Font Quer (1989) la hace sinónima de olivarda. En la comarca de Grazalema, me informa González-Tejero, se conoce el dicho: ‘Altabaca, arre mi jaca / matagallo pare mi caballon. 
provincia de Jaén. El citado botánico recoge, además, mosquera, mata mosquera y yerba mosquera en comarcas que forman parte de la provincia de Almería, la Sierra de Oria y zona alta del Valle del Almanzora ("Mosquera, como llaman a la Altabaca por el uso que hacen della", 1805: 204), que enlaza con el modo de llamarla en Murcia; aunque su extensión en Almería es bastante más extensa, pues, además de toda la Cuenca del Almanzora (Cf. Pardo Berbel, 1987: 72), se usa en el Campo de Níjar, Sierra Alhamilla y rebasa por el Oeste el término municipal de Almería (Rojas Clemente en esta ciudad recoge yerba mosquera, con la equivalencia "Erigeron viscosum"), en todos estos lugares alterna con olivarda (para la distribución de mosquera y olivarda; véase el mapa n. ${ }^{\circ} 3$ ). Otro nombre, aunque menos usual, en las tierras almerienses es pegajosa (Rueda Casinello 1983: $s$. v.). Las formas matamosquera y mosquera no las recoge el DRAE, aunque se usan en una amplia zona para designar la "Dittrichia viscosa", pues, como otros orientalismos, se extienden, también, por el noreste de la provincia de Granada, Baza (Blanca 1991: s. $v$. matamosquera), Cúllar-Baza (Salvador 1957: II, 42) hasta unirse con la región almeriense arriba citada. Como se ha adelantado, mosquera o matamosquera aparecen en la región murciana, desde el norte (Gómez

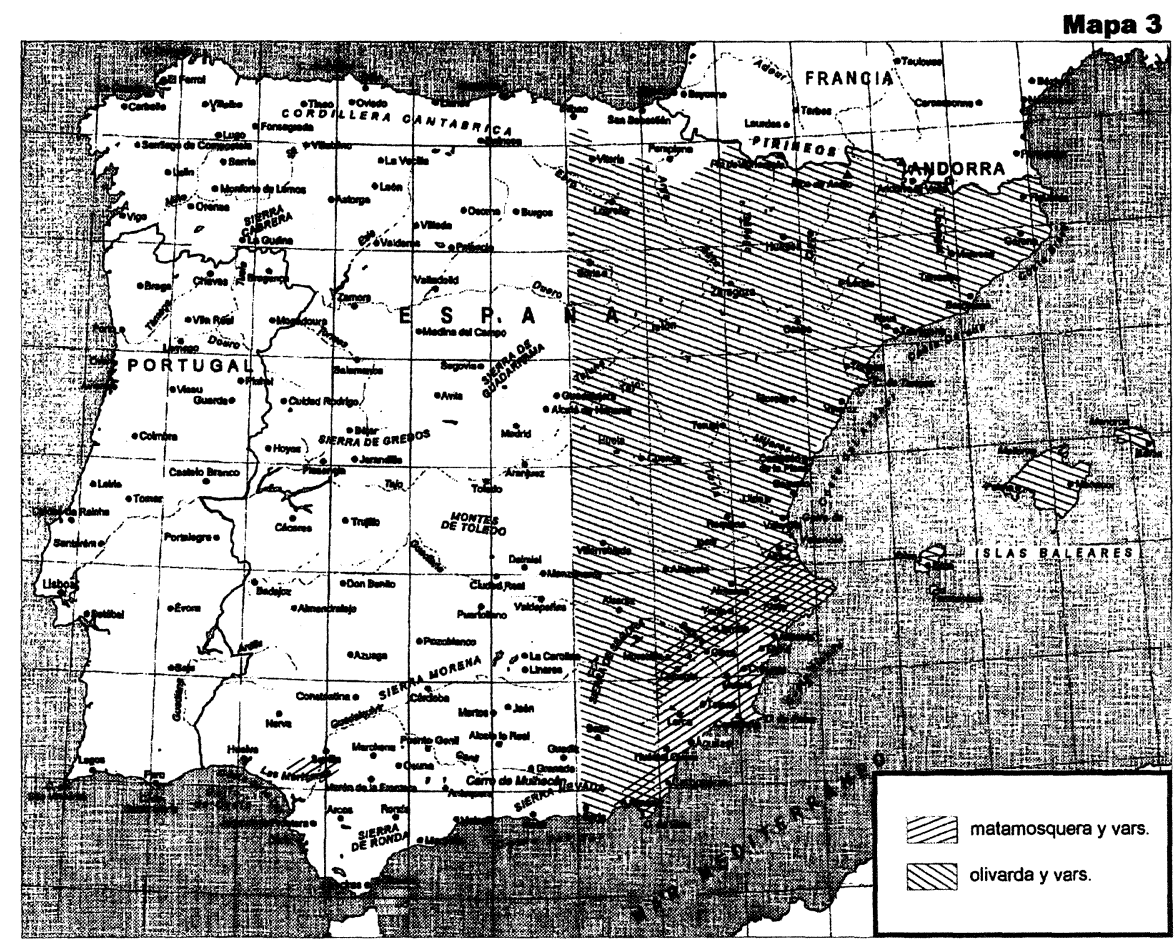


Ortín 1991: s. v. mosquera) hasta el sur (Sevilla 1990; García Soriano 1932: $s$. $v$. mata mosquera); en la provincia de Alicante (documentado, entre otros lugares, en Yecla), donde alterna con matamoscas (Morales 1996: 49) ${ }^{25}$, y como herba mosquera se prolonga por otras comarcas de la Comunidad de Valencia (Cf. Morales 1996: 49); aunque la forma predominante, conforme se asciende hacia el Norte - en tierras de habla catalana- es olivarda, donde aparecen las vars. mixtas julivarda, juliverda y joliverda entre otras en Castellón (Mulet 1987: 59) ${ }^{26}$; que acomodadas a la fonética del dialecto del Alto aragonés oscense, la comarca de Mozón, son cholibarda y chulivarda, (Ferrández 1982: 280; Morales 1996: 49).

La forma léxica altabaca se inicia en la Alpujarra Baja almeriense hasta Felix, y enlaza con la Alpujarra Alta granadina (donde aparecen las vars. altarraga, atarraga, tárraga, atárraga; Cf. García de Cabañas 1975: s. $v$. altarraga ${ }^{27}$; precisamente entre las dos provincias corre un arroyo llamado los Altabacales. Según la información de que dispongo, altabaca y sus variantes se extienden, de Norte a Sur, hacia occidente en una línea sinuosa, desde Santander, en el Cantábrico, hasta el límite entre las provincias de Granada y Almería, en la costa mediterránea -atabaca está documentado en Santander, altabaca en Madrid, Jaén, Granada y Andalucía Occidental, especialmente en la provincia de Cádiz (Toro Gisbert 1920: $s . v$, y Alcalá Venceslada 1980: s. $v$., la recogen entre las voces andaluzas)_; y es muy viva en gran parte de las Islas Canarias (DHLE, s. $v$. altabaca, Morales 1996: 49), también aparece en Portugal con la forma távega ${ }^{28}$; mientras que olivarda tiene su dominio en una amplia zona que va hacia oriente de la citada línea. El término olivarda es el empleado en la Rioja alavesa, Aragón (olibarda en Asso, 1779; Andolz, 1984: s. v.); Cataluña; Mallorca; la Comunidad valenciana (Morales 1996: 49; DECLLC, s. $v$. oliva); en tierras albaceteñas: en las Sierras de Segura y Alcaraz (Verde 1998: 24) y en el Campo de Montiel (Esteso 1992: 346); y es mayoritaria en la provincia de Jaén.

La mayor parte de los nombres que recibe esta planta, tiene su origen bien en la viscosidad sus hojas (pegajosa), bien en la utilidad que

25 Alcalá Venceslada (1980) recoge matamoscas, sin localizar, identificándola con 'altabaca'.

26 El DECLLC explica estas formas mixtas como una contaminación de jull< <OLIUM.

27 Rojas Clemente da la voz atarraga para el Reino de Jaén (que el DCECH: $s . v$., cree que la Academia, al recogerlo de este botánico, hace una mala lectura por atavaca). Hoy en la Sierra Mágina (Jaén) se documenta tárraga (Blancoana, 15-1998-, 16).

28 Para esta planta aparecen distintas vars. tádega, tágueda, taveda y alfavaca en Portugal y las Azores; cf. Martínez Almoyna 1998: ss. vv. 
esta sustancia tiene para atrapar insectos: mosquera o mata mosquera (véase infra, \$4.3.), matamoscas en Alicante, berba mosquitera en Valencia, pulguera en Cádiz y Valencia. El término olivarda, está en los repertorios de los botánicos hispano-árabes en los que se muestran las virtudes de esta hierba medicinal: libárda es la forma mozárabe recogida por el Anónimo Sevillano de hacia fines del siglo XI (Asín Palacios 1944: 156), y por el judío Ibn-Buclarix con las vars. ulivârdo, alivârdo (Simonet 1967: s. $v$. olivarda). Es un mozarabismo que se extendió por la zona oriental y una extensa zona central de la Península. El DCECH, s. v. olivo, sin embargo, considera el término un préstamo del cat. en castellano. Aceptando que su nombre sea un derivado de olivo, me parece más verosimil la tesis que dio Simonet (1967), que lo explica -apoyándose en la descripción que de esta planta hace el Dr. Laguna- porque sus "hojas [son] como las de olivo, empero vellosas y grassas"; que la que dan Corominas-Pascual (DCECH: s. v. olivo), o solo Corominas (DECLLC: $s . v$. oliva), que buscan la causa en la "agalla en forma de aceituna que cierto parásito engendra en esta plantan; pues, en mi experiencia - y en la de los botánicos e informantes consultados-, esta circunstancia en la mata debe ser accidental o poco notoria, pues nunca ha sido observada.

En conclusión, para esta planta hallamos en las tres provincias andaluzas estudiadas, el término altabaca y vars., que se extiende por el resto de Andalucía y zonas centro-occidentales de la Península Ibérica y Canarias, y dos nombres de localización oriental, olivarda, con un área muy extensa, que abarca el centro y oriente de la Península; y matamosqueramosquera, con una zona más limitada, que comprende parte del este y sureste peninsular (el DEA, no obstante, recoge mosquera, como general, 2. ac., para la "Rosa sempervirens L.").

\subsection{Estudio etnográfico}

El uso tradicional y principal que ha tenido esta hierba en gran parte del litoral oriental almeriense, ha sido el de atrapa-moscas; para ello durante el verano se colgaba del techo en las casas y establos, a ella acudían las moscas atraídas por la sustancia viscosa y quedaban inmovilizadas; cuando anochecía, se metía la olivarda en un saco, se cerraba y fuera de la casa se apaleaba para matar las moscas que iban adheridas a las matas. Al día siguiente se colgaba una nueva planta y se repetía la operación ${ }^{29}$.

29 Esta planta se ha utilizado desde tiempo inmemorial para combatir las moscas y las pulgas: ya en la aljamía de los árabes, junto a libarda, aparecen los nombres 
Otro uso que le han dado los pastores de la zona es, mezclada con paja, el de cama del ganado para ahuyentar las pulgas; en la zona almeriense donde se cultiva la uva del tipo Ohanes, se emplea para la operación que localmente se llama engarpe, es decir, para la fecundación artificial de este tipo de parras (Rueda Casinello 1983: s. v. matamosquera); también los muchachos han usado sus hojas como "tabaco" para fumar, en varias de las zonas estudiadas (Cf. igual uso en la zona de Monzón en Huesca, Ferrández 1993: 280; y el nombre de tabaquera, que en otros lugares también recibe la planta). En Bedmar (Jaén) se ha empleado para dar buen olor a la fruta, cuando ésta se almacenaba (Blancoana, 15 1998- 16).

En la medicina popular ha tenido, también, un uso bastante generalizado, cocidos sus tallos y hojas (a veces mezclados con la "Sideritis hirsuta"), se emplea en Almería y en Granada (González-Tejero 1989: s. v. "Dittrichia viscosa") para desinfectar y curar las heridas tanto de las personas como de los animales ${ }^{30}$; sus hojas se han utilizado en el Campo de Nijar, además, para curar la eripsipela (sipela) ${ }^{31}$, para ello, al mismo tiempo que se rezaba una oración, se frotaban las hojas por la cara (algunos señalan que tienen que ser nueve hojas y durante nueve días); en la región de Níjar y Carboneras se utiliza, además, para curar trastornos ginecológicos, para lo cual se confecciona un decocto con tallos de olivarda, y se toman localmente los vapores (Torres Montes 1994: 517-518; y Martínez Lirola 1997: 322). En la Cuenca del Almanzora, además de como vulneraria, se ha venido empleando para combatir el binchazón (García Ramos 1987: s. v. olivardiza) ${ }^{32}$; y en Sierra Mágina (Jaén) como astringente (Espantaleón 1947: 77). Por último, hay que señalar que sirve de forrajera en Almería (igual en Aragón, Cf. Ferrández 1993: 280); también en esta provincia, seca se ha usado para hacer escobas para barrer la era.

moxcato y pulcaira (Simonet 1967, s. v. olivarda); Laguna (1968: 350) nos dice que "extermina los moxquitos y mata las pulgas", de ahí que en latín se llame Pulicaria y añade: "Puesto un manojo de conyza [olivarda] en una parte de la casa, trahe hacia sí toda la polilla o gusanon (loc. cit.).

30 Como vulneraria y cicatrizante se utiliza en otras zonas de España en las Sierras de Segura y de Alcaraz en la provincia de Albacete (Verde 1998: 225; Esteso 1992: 346); en Murcia (Obón de Castro 1991: s. v.), y Huesca (Villar 1987: 91 y 208).

31 Cuando alguien contraía la enfermedad se decía la expresión carga sipela, cuyos síntomas son el enrojecimiento de los ojos y pómulos

32 En el Maestrazgo (Castellón) y en Monzón (Huesca), además de vulneraria y antiflamatoria, se ha utilizado como antiséptica, el decocto de las sumidades de las flores en baños dérmicos y las hojas para hacer un emplastro que combate las lumbalgias, y los dolores de reuma (Mulet 1987: 59; Ferrández 1993: 280). 


\section{MATAPOLLO(S) (Daphne gnidium L.)}

5.1. Este arbusto leñoso de la familia de las timaleáceas, conocido en el dominio español, en general, con el nombre de torvisco, que puede sobrepasar el metro de altura, tiene ramas esbeltas, y hojas estrechas y lanceoladas, las flores de color blanco y los frutillos carnosos, que al principio tienen una tonalidad verde, luego roja y, por último, negra.

\subsection{Estudio lingüistico}

El DRAE recoge para el 'torvisco' —además del fem. torvisca, que también da como general- los siguientes sinónimos bolaga en Cádiz y en Murcia (aunque creo que en la última provincia se trata de otra planta, la "Thymalaea hirsuta", que por error García Soriano 1932: s. v., identifica con el 'torvisco', de donde la Academia toma la información); matagallina en la Rioja ${ }^{33}$, y matapollo (masc.), que lo hace propio de Murcia (sin embargo, el DEA, s. v., siguiendo una vez más las sinonimias de Font Quer, 1989, da esta voz como general). Es cierto que esta última designación se extiende por toda la región murciana (Sevilla 1990; García Soriano 1932; Gómez Ortín 1992: s. v.); no obstante, su área léxica es mucho más extensa, pues se extiende por parte de Albacete (varios municipios orientales de la Sierra de Segura; Cf. Verde 1998: 31 y 240), todo el Levante peninsular, Mallorca (Guillén García 1974: s. v.; Morales 1996: 46-47), donde en tierras de habla catalana, junto a la forma matapoll, aparecen las vars. matapoy, matapollera y matapollar); parte de Aragón, no sólo en la franja de habla catalana, sino, además, en el Bajo Aragón (Andolz 1984: $s . v$.); y una estrecha zona de Andalucía Oriental en las provincias de Almería, Granada y Jaén - donde he encontrado, además, la vars. minoritarias matapollera matipollera (García Ramos 1987: s. v.)—. Para la distribución de matapollo(s) y variantes; véase el mapa n. ${ }^{\circ}$.

Del área de matapollo en el antiguo Reino de Granada nos da información Rojas Clemente a principios del siglo XIX (1805: 195, 203 y 209; 1806: s. v.), que en la provincia de Almería, coincide, grosso modo, con los datos de que dispongo en la actualidad (Cf., además, Pardo Berbel

33 Este término es también común del dominio cat. (Font Quer 1989: 388; Mulet 1991: 57; Morales 1996: s. $v$. "Daphne gnidium"). El nombre matagallos, que no recoge el DRAE, designa en gran parte de Andalucía y el sureste peninsular la "Phlomis purpurean. 
1987: 73); en la citada provincia se extiende por la Cuenca Alta del río Almanzora (Bayarque, Albanchez, Cantoria), Sierra de Oria, los Vélez ${ }^{34}, y$ Huércal-Overa hasta la provincia de Murcia. En la de Granada, aunque Rojas Clemente, 1806, localiza matapollo en la comarca de Baza, hoy, sin embargo, no lo he podido documentar. En la provincia de Jaén, donde domina casi exclusivamente torvisco, torovisco y torovizco ${ }^{35}$, encuentro do-

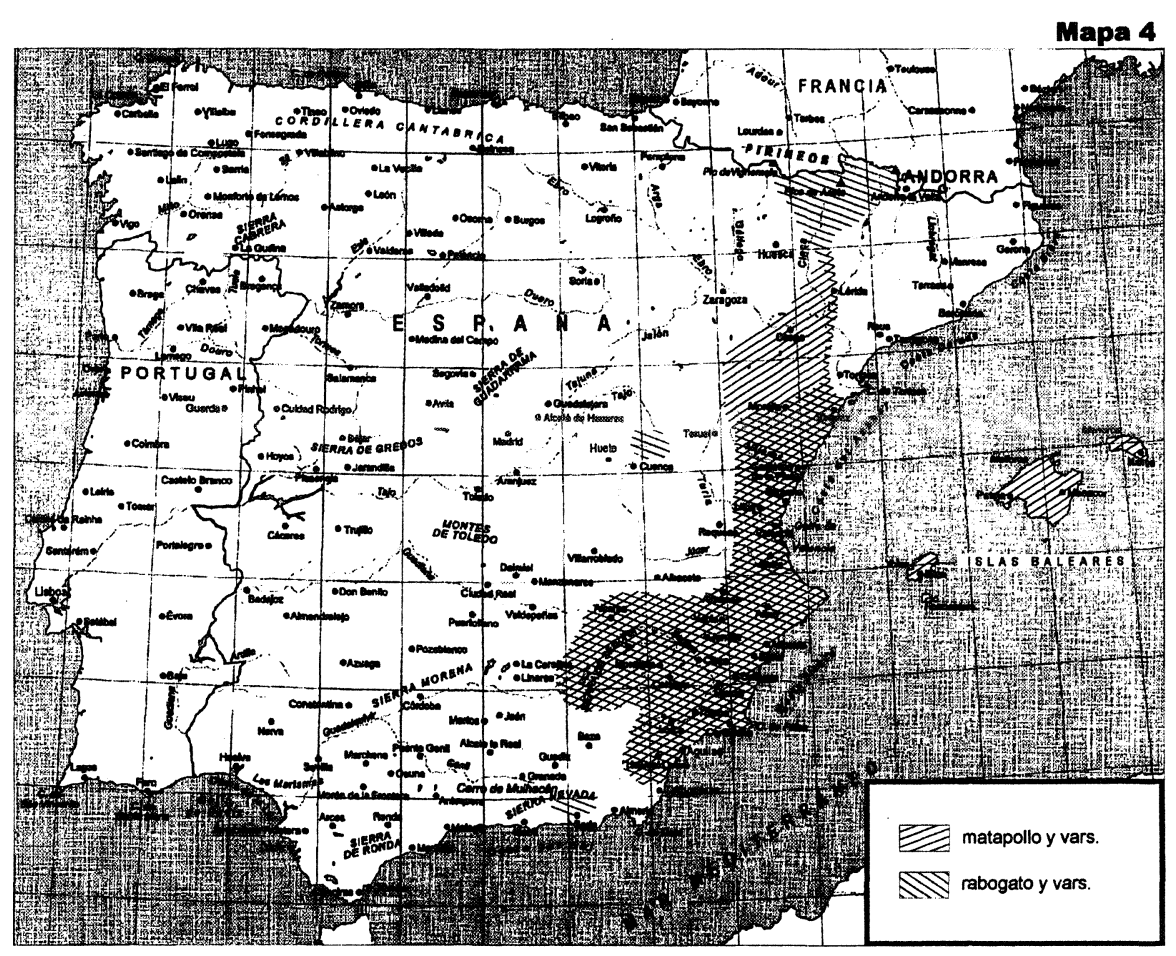

34 Muñoz Renedo (1963: s. v.) identifica el matapollo en Vélez Rubio con la "Thymalaea tinctoria"; aunque en la Flora Hispánica no se documenta esta planta en esta zona; igual referente da Andolz 1984: $s$. $v$., para este término en Aragón.

35 El término absolutamente dominante en las tres provincias orientales, como en el resto de Andalucía, es torvisco, que alterna con las variantes fonéticas torvizco, torovisco (esta última forma la encuentro en Jaén, en Carchalejo y Cazorla; y en Almería, en Nijar y el Valle Alto del Andarax) y torovizco (Andújar). La forma torovisco está ya documentada en el XVI, en el sevillano Lope de Rueda (véase DCECH: s. v. torvisco). Esta anaxtisis, influida por una etimología popular, es común en otros puntos de Andalucía; la recoge Alcalá Venceslada, 1980, sin localizar comarcas concretas. En el XVIII, el párroco de Padules (Almería), en la contestación al cuestionario de Tomás López ([1795] 1986), en la respuesta n. ${ }^{\circ} 16$ dice: "Está poblado [el monte] de romero, tomillo, aljedreas, arlos, gualdas, espinos, lentiscos, matagallos, toroviscos y otras que llaman estepa [...]" (López 1986: 90). 
cumentado matapollo en Villanueva del Arzobispo y en la Sierra de las Cuatro Villas, aunque en estas localidades convive con la denominación general, y en otros casos este término designa otra planta, una "Reseda sp." (Blancoana, 9 -1992-63); de un pastor de la Sierra de Jabalcuz recojo la variante matagallo, aunque no estoy seguro de que se trate de la misma planta.

Respecto de su origen, Corominas (DECLLC, s. v. matar) sostiene que la forma catalana matapoll —que identifica con el "Delphinium staphisagria" y con nuestra planta, el "Daphne gnidium", ambas tóxicas - es un compuesto del postverbal mata (> matar), más poll 'piojo', y 'cría de las aves' o 'gallo joven'; “el nom s'explica — dice el citado lingüista— porquè s'usa com a insicticida de la mengilla", es decir para combatir los parásitos del hombre (uso que está documentado para este "Delphinium", al que en castellano se llama piojera).

Sin embargo, no creo que para el 'torvisco', mata (en matapoll, matapollo) proceda de matar; y poll, tenga el significado de 'piojo' sino de 'cría de gallinácea' o 'gallo joven' (Cf. cómo en catalán esta planta recibe también el nombre de matagallina). Los compuestos de mata más un nombre o un adjetivo son numerosos para designar las plantas; aunque hay que distinguir los casos en que el primer término del compuesto es un postverbal del verbo matar, por los efectos mortíferos de la planta, y en este caso el segundo elemento se trata de un sustantivo que designa el animal sobre el que la planta actúa mortalmente (Cf. matalobos "Aconitum lyccoctonum" y "A. napellus", por ser utilizado el veneno de esta planta en los cebos para matar los lobos); de aquellos otros, que son el mayor número de casos, en los que el primer elemento del compuesto se trata del sustantivo mata 'planta baja de tallo leñoso', y el segundo puede ser, bien un nombre que tiene por referente un animal u objeto que se relaciona con la planta por su semejanza o cualquier otra característica (matagallo "Phlomis purpurea", por la inflorescencia que se asemeja a la cresta del gallo; matamosquera "Dittriquia viscosa" por la peculiaridad que tiene de quedar pegadas las moscas a sus hojas, como se ha visto en $₫ 4$.1.; matacandil "Sisibrium irio L."); bien un adjetivo o adyacente que señala una cualidad o uso del vegetal (matayesquera "Artemisia herba-alba"; matica blanca Helichosymum stoechas", etc.). En el caso de matapollo (matapoll), según creo, se trata de este segundo grupo, pues - aunque, en efecto, la planta sea tóxica- las aves, especialmente las gallináceas, comen sus frutos con delectación (Cf. Sagredo 1987: 288, al dar las características de esta planta dice "su drupa gusta mucho a las perdicesn); de ahí que se use como cebo para cazar perdices en algunas zonas hispánicas, como en la Sierra de Segura (Verde 1998: 
240), o en Alhama (Murcia), donde hacen con el torvisco unos lazos que sujetan con un pelo de cola de caballo para cazarlas vivas (Obón de Castro 1991: 85); o para cazar pájaros en el Bierzo (DCECH: s. v. torvisco). No hay que olvidar que las crías de las aves, especialmente el gallo joven y el macho de la perdiz, entre cazadores y gente del campo, llevan, por antonomasia, el nombre de pollo; de la afición de esta aves por el torvisco ha surgido, según creo, el compuesto en cuestión.

\subsection{Estudio etnográfico}

Esta planta tiene en nuestra región, y en otras zonas peninsulares un carácter mágico de especiales efectos beneficiosos. Tradicionalmente se ha utilizado para curar el "mal de ojo" de los niños, para ello una persona que tuviera "gracia" ('que por nacimiento tuviera ciertas dotes para curar') debía poner al alba varias ramas de torvisco en los cruces de caminos ${ }^{36}$. También por sus efectos mágicos hace - me aseguran-que las hembras recién paridas de los animales expulsen las parias, para ello, en una práctica muy generalizada en toda la región, se trenzan alrededor de la barriga del animal unas ramas de torvisco (igualmente utilizado en Murcia, Cf. Obón de Castro 1989: 85; Gómez Ortín 1991: s. v. matapallo); también trenzadas sus ramas alrededor de la barriga o del cuello cura - me afirman - las diarreas del ganado (y, en el caso de las personas, en Carchalejo, Jaén, se lleva en la mano una tira de la corteza de esta planta hecha un nudo); en Valdepeñas de Jaén se usa para curar los "uñeros" de los animales, y en Castillo de Locubín para eliminar las sanguijuelas (Blancoana, 9 -199250-59; y Blancoana, 11 - 1994 - 110). En el Campo de Níjar (Almería) se ha utilizado, además, para quitar las verrugas, para ello se apalea la planta hasta que quede sin hojas (véase $\$ 3.3$.); igual uso se da en Sierra Mágina en Jaén (Blancoana, 15 - 1998- 36 y 37) ${ }^{37}$; además, en la comarca almeriense señalada se ha empleado como predictivo, pues según la planta diese más o menos fruto se ha tomado como indicio de la abundancia o escasez del próximo año agrícola.

36 Guichot y Sierra (p. 341) nos describe en "Superticiones andaluzas" que "para curar el mal de ojo en los niños, se reune tal cantidad de torviso, cuanto sea el peso de la criatura y se tira al tejado, cuando la planta se seque desaparece el mal" (Folklore andaluz, dirigido por A. Machado y Álvarez, Demófilo, 1882-83; ed. facsímil, Sevilla: ed. Alintor, 1981).

37 En el Maestrazgo (Castellón) es la corteza del torvisco la que se emplea para estrangular los granos (Mulet 1987: 57). 
Otro uso tradicional que se ha dado al torvisco ha sido el envarbascar los remansos de los ríos para adormecer los peces y poder pescarlos (Sierra de Andújar y Cazorla, en Jaén). En la Sierra de Oria (Almería) se considera su raíz venenosa, de ahí que se estime que no son comestibles las setas que crecen alrededor de esta planta; aunque hay un crecido número de encuestados que no la cree venenosa; en Nijar-Cabo de Gata se mastica su corteza para combatir el dolor de muelas; y se inhala su vapor, cocido con cantueso, contra la ronquera; el fruto se usa para aliviar los trastornos digestivos; y éstos, además, se ingieren en un número impar para curar distintas enfermedades de los ojos (Torres Montes 1994: 525-526; y Martínez Lirola 1997: 158); y en Albox y la Cuenca del Almanzora, sin embargo, se utilizan para depurar la sangre (Cf. García Ramos 1987: s. v. matapollera). Rojas Clemente (1805: 203) documenta el uso del matapollo en Oria para teñir de verde las colchas que se hacían en el pueblo (véase supra: boja, \$3.3.). En la provincia de Granada -me informa González-Tejero- se da a los niños para combatir la incontinencia urinaria.

Sólo en Granada (la Alpujarra y Baza) tengo información de que se haya usado como purgante (Serrano 1932: 453; de la Blanca 1991: s. $v$. "Daphne gnidium"), empleo tradicional y generalizado de esta planta desde la antigüedad, del que nos informa el Dr. Laguna: "Bebido el meollo de XX granos, purga por abaxo la cólera, la flema y los humores aguosos", aunque advierte que "tiene mucho de venenoso estas dos especies de plantas [thymalaeas], y ansi non devemos administralas jamás a ningún hombre flaco. Salvo sino queremos embiarle con cartas al otro mundo" (1968: 174) ${ }^{38}$.

En el Campo de Nijar, comarca donde se le designa por torvisco y variantes, es conocida una adivinanza que se decía en forma de copla, en la que se reconstruye su nombre: "Toro me llaman por nombre,/ y visco por apellido/ el galán que me acertara/ tendrá que ser bien entendido" 39 .

38 Actualmente también se usa en el Sáhara occidental como purgante y abortivo, cociendo sus hojas y la corteza del tallo (Bellakhdar 1978: s. v. "Daphne gnidium"). Como insecticida y antiponzoñoso, muy usado en Levante y Cataluña (Mulet 1987: 57; DECLLC: $s$. $v$. matapoll), no lo he documentado en nuestra zona de estudio.

39 Variantes de esta adivinanza llegan a la zona occidental de Sierra de Segura, entre las que recojo la siguiente: "Toro me llamo de nombre/ y visco por apellido,/ si quieres saber mi nombre/ ya te lo he dicho". 
6. MOJINO MOJIGATO (Anacyclus clavatus (Desf.) Per.)

6.1. Esta planta de la familia de las compuestas se caracteriza por sus vistosas flores, muy semejantes a las de la margarita y del crisantemo, con lígulas blancas y el centro de la flor amarillo - de ahí que en algunas zonas de Almería, Granada y Jaén se le llame también margarita, manzanilla gorda y manzanilla loca- suele habitar las tierras roturadas y de labor, por eso se la considera una mala hierba. Su altura no sobrepasa los $50 \mathrm{~cm}$. y sus hojas son lanceoladas divididas en lóbulos lineales. Otra planta, semejante a ésta, el "Chrisantemum coronarium L." recibe también el nombre de mojino, aunque para deshacer la homonimia normalmente va acompañado del adjetivo amarillo.

\subsection{Estudio lingüístico}

La forma mojino (masc.) para designar el "Anacyclus" se extiende por el centro y oriente de la provincia de Almería, y convive en el Campo de Níjar con aquéllas que llevan un adjetivo especificativo: mojino blanco, mojino fino; y la variante, probablemente por etimología popular, mojigato aparece en la región almeriense que se inicia en Carboneras y llega hasta Pulpí (en el límite con la provincia de Murcia), y alterna con margarita y margarita borde en el norte de Almería, estas últimas debidas al parecido con la "Bellis perennis".

El área de mojino se inicia en la zona del litoral más oriental de la Alpujarra almeriense (véase mapa n. ${ }^{\circ}$ 2), se extiende por los municipios de Almería, Cuenca Baja del río Andarax, Sierra Alhamilla, Níjar —donde alterna con matica el amor-, hasta Carboneras, y por la Sierra Cabrera enlaza con la Sierra de los Filabres y las tierras del Almanzora (en Alcóntar también aparece flor el amor), donde mojino comienza a alternar con mojigato, que es la denominación exclusiva en las zonas más próximas a la región de Murcia (véase ALEA, II, m. 296; adenda margarita "Bellis perennis" ${ }^{40}$; Torres Montes 1995: 76; Pardo Berbel 1987: s. v. mojigato). Es también conocido el sintagma margarita borde o margarita (Cf. mar-

40 Al preguntar por la margarita - se informa en la citada lámina del ALEA- las respuestas se mezclan con la de la margarita silvestre, que se recogen en una adenda en la misma lámina. Se recoge mojino en los siguientes puntos de Almería: Felix, Benahadux, San José (Nijar), Carboneras y Tahal; y mojigato en Carboneras, Gafarillos (Sorbas), Vera, Perulera, Palomares-Villaricos (Cuevas), y Pulpí. 
garita borda en Alfaro, La Rioja, para el "Chrisantemum frustecens"; Martínez Ezquerro 1994: 104).

El término mobino, sin restos de la antigua aspiración, aparece en Murcia, que Sevilla (1990: $s . v$.) da como voz regional para la 'margarita silvestre', y la define como planta que nace en los yermos, de una sola fila de pétalos blancos y con el botón central amarillo; también la recoge como murcianismo García Soriano (1932: $s$. v.) con el valor de una variedad de la 'margarita silvestre'; y en Orihuela el mohino se considera como una 'hierba mala de la huerta y del monte' (Guillén García 1974: 141); en la región valenciana se encuentra la voz moixos para el "Chrynsatemum coronarium" (Albertí 1961: s. v.) ${ }^{41}$. Colmeiro (1885-89), ss. vv. "Chrysantemum coronarium" $\mathrm{y}$ "Ch. segetum", recoge para estas plantas los términos mohino y mogigato; aunque no los localiza; otros nombres vulgares que se dan a estas plantas son magarza, manzanilla de flor dorada, manzanilla loca, gabanzo, corona de rey y santinomia.

En Granada y en Jaén no he encontrado las denominaciones mojino mojigato para las referidas plantas; al "Anacyclus" en Baza se la conoce como manzanilla gorda y ojo de los sembrados (Blanca 1991: 24) ${ }^{42}$; en la costa motrileña el nombre general es manzanilla loca; y en Sierra Nevada, galas de muerto (Boissier 1839: s. v.). En tierras de Jaén, en Sierra Mágina y en la zona más nororiental tanto de esta provincia como en la de Granada, el "Anacyclus" y la "Bellis sylvestris" se llaman margarita y margarita silvestre (Blancoana, 15 -1998- 11 y 42; ALEA, II, m. 296).

El origen de mohin, mobino y amobinar es controvertido; el DRAE (que da para mobino el significado 'triste', 'tedioso', 'meláncólico') coincide con García de Diego (DEEH: 4.468), las hace derivar de la onomatopeya mof; sin embargo, el DCECH - s. v. mohino- sigue a Dozy (Suplemen II: 790), y propone el adj. ár. mubim 'malsano', cruzado con otro adjetivo hispanoárabe; quizá de esta acepción provenga el valor despectivo que esta palabra tiene, además, en gran parte de nuestra región (en Sevilla mojino es 'el trasero', 'ano' Cf. González Salas 1994: s. v.) ${ }^{43}$. Respecto a la aparición de la jota, el sonido velar [x] o la aspiración [h],

41 Los Sorbus ("S. aria"; "S. aucanaria") reciben en la Comunidad valenciana los nombres de muxera, moixera, mojera, moixero, muxera serval (Morales 1996: 130).

42 Por las características físicas de esta planta, cuando se encuentra en las tierras sembradas, lleva el nombre de ojo; que en la Comunidad valenciana es ull de bou, también en español ojo de buey.

43 El DEA, s. v. mojín, lo recoge como jergal con el valor de 'trasero, ano'. Un grupo musical de rock de Sevilla lleva el nombre de Mojinos escocíos. Alcalá Venceslada registra la voz mobíno como andalucismo, con dos acepciones: el gentilicio familiar de Alcaracejos (Córdoba), y 'pájaro parecido a la urraca con plumas azules'. 
donde la norma culta en la escritura pone una $h$, no tiene otra razón que el resto del antiguo fonema medieval aspirado $/ \mathrm{h} /$ que se mantiene en gran parte de Andalucía y llega a la Alpujarra almeriense; en el resto de la provincia ha pasado al sonido más próximo, la $[\mathrm{x}]$ castellana.

\subsection{Estudio etnográfico}

El uso principal que se le ha dado a esta mata es el ornamental, tanto en la zona almeriense como en la Sierra de Mágina en Jaén (Blancoana, 15 -1998- 11 y 42); cuando está en flor se coloca en jarrones como centro de mesa. También sirve como forrajera del ganado lanar y caprino; y sus tallos y hojas tiernas se han empleado en primavera como alimento humano, para lo cual previamente se cuecen ${ }^{44}$. Ha sido tradicional entre los niños y jóvenes su uso como predictivo amoroso, del mismo modo que se ha utilizado la margarita, con una flor del mojino, y ante la pregunta de "¿me quiere o no me quiere?", se va deshojando la flor, acompañado de un "Si / no", el resultado lo da la última lígula; por ello, también en algunos puntos de esta zona se le llame flor el amor y matica el amor.

No he recogido en la zona almeriense estudiada el "Anacyclus" para uso medicinal; sin embargo sí se documenta en Jaén ${ }^{45}$, en Carchalejo, donde se utiliza en infusión contra los trastornos digestivos (Blancoana, 15 $-1998-42)^{46}$.

44 Hay un plato típico de la zona de Níjar que se cocina con varias hierbas autóctonas: se pican y se fríen los tallos y las hojas tiernas del mojino con collejas ("Silene vulgaris"); acelguillas ("Beta maritima"), patagallina ("Calendula arvensis"); capitana ("Limonium arvensis"), cardo-cristo (Scolymus hispanicus") y un tallo de amapola; a continuación se vierten en una olla, donde previamente se han sofrito y cocido tomates, cebollas, tocino y carne de cerdo con garbanzos y patatas, a lo que se le ha añadido pimiento seco, una pizca de canela y sal; una vez consumida el agua, la comida está dispuesta para servir (véase Martínez Lirola 1997: s. v. "Silene vulgaris").

45 También en Castellón el Anacyclus se ha utilizado para cicatrizar heridas y como antiflamatoria y antiespasmódica (Mulet 1991: $s . v$.). Por lo que respecta al "Chrysantemum coronarium" se ha empleado en Sáhara Occidental, además de pasto, para curar la sarna de los animales y como vermífugo (Bellakhdar 1978: s. v. "Anacyclus clavatus").

46 Recojo en esta provincia también rabo de gato, pero haciendo referencia a otras plantas, la "Phlomis lychnitis L." en Cazorla (Blancoana 9-1993- 55, 65; ibid. 11 -1994- s. v.; y sin localizar zona para la "Trifolium cherleri" (Espantaleón 1947: s. v.). 


\section{RABOGATO (Sideritis hirsuta L.; otras sideritis)}

7.1. Se trata de una matilla leñosa de la familia de las labiadas. Tiene escaso porte, en general (a excepción de la "Sideritis foetens", que suele llegar a $1 \mathrm{~m}$. de altura); se distingue por sus largos tallos y pequeñas hojas, parecidas a las del marrubio, aunque más estrechas, que desprenden un olor intenso, además de tener un cáliz con dos labios, de los que destaca el superior por ser más largo y ancho y con flores en las que en el género predomina el color amarillo ("S. hirsuta", "S. glacialis Bois.", "S. angustifolia Lag."), pero también en otras aparece el blanco "S. leucantha Cav.", y en ocasiones mezcladas con tonos purpúreos. Crece en tierras abandonadas, bajo monte, lugares rocosos etc. El DRAE recoge para este género el nombre siderita.

\subsection{Estudio lingüistico}

Estas labiadas presentan en nuestra zona de estudio, como ya se ha dicho, varias especies, que suelen recibir indistintamente la misma denominación; aunque ésta varía según la zona o comarca, de modo que no forman franjas uniformes, y así, en ocasiones, unas áreas léxicas se intercalan en otras. Según se avanza de Oeste a Este los términos recogidos son zabareña y vars. (fem.), garranchuelo y vars. (masc.), y rabogato y vars. (masc.). Ninguno de los nombres que recojo en la región aparece en el DRAE con la acepción que aquí traemos; y el único caso -el de garrancbuelo- en que da por referente una planta, se trata de una gramímea, posiblemente la "Digitaria sanguinalis L." ${ }^{47}$.

El término zabareña es el que predomina, como en el resto de Andalucía, en las tres provincias orientales. El área se extiende por las zonas central y occidental, de Norte a Sur, con vars. fonéticas: zabareña, con aspiración, en la parte occidental de la Alpujarra almeriense, y en Granada (Cf. zabareña de la sierra para la "S. glacialis" en Sierra Nevada o sajareña, con seseo en Carratraca en Málaga; véase Medina 1864: s. v. "S. hirsuta"; Colmeiro 1885 IV: 394; Gacía Cabañas 1975: s. v.; Titos s. a.: 87; Morales

47 Para la "Digitaria sanguinalis", carrancbuelo en la costa tropical granadina (Marín 1984: s. v.) y garranchuda en Alicante (Morales 1996: 49); en el Condado de Huelva, garranchuelo es el nombre que se da a una planta sin identificar, aunque de fam. distinta de la que aquí tratamos porque se define como "planta dañina de flores violáceas" (Medina Molero 1980: s. v.). 
1996: 127), desde donde se extiende a la Andalucía Occidental; zajareña, con la $j$ castellana [x], en la provincia de Jaén, en la zona meridional, en gran parte de Sierra Mágina, las Villas y llega a Cazorla (Cf. Blancoana, 11 - 1994 - 79); en una franja nororiental de la de Granada - que alterna con sajareña en Sierra de Baza (Cf. Blanca 1991: 253)-; y en una gran zona central y la occidental de la de Almería - donde, además, se documentan las vars. jajareña y jareña en puntos de los municipios de Almería y Níjar (Cf. Martínez Lirola 1997: 273)—; aunque también aparece, por enclaves, en algunas comarcas orientales almerienses, en Sorbas, Carboneras, gran parte de la Sierra de los Filabres, como en Velefique, etc ${ }^{48}$.

El sustantivo garranchuelo, en Almería, y la var. garranchillo, en Jaén, se intercalan en una zona entre rabogato y zajareña. En la provincia de Almería se extiende por el término municipal de Nijar y por Sierra Cabrera (Cf. Torres Montes 1994: 514; Martínez Lirola 1997; Lahora Cano 1997: 112) ${ }^{49}$; en la de Granada, en localidades de la zona nororiental también se da el nombre de garranchuelo para la "S. hirsuta sub. Nivalis", y "S. funkiana", en Baza, Caniles y Graena (González-Tejero 1989: ss. vv.); y en Benamaurel para una siderita sin identificar; en Jaén, la var. garranchillo está documentado en las Sierras de Segura y Cazorla para la "S. hirsuta" (Blancoana, 9 -1992- 51 y 56; ibid. $11-1994$ - 71).

Por último, el término de rabogato (y la var. rabo de gato) predomina casi de forma absoluta en la comarca más oriental de la provincia de Almería - Cuenca Alta y Media del Almanzora, Sierra de Oria, y los Vélez (Cf. García Ramos 1987: s. v. rabogato; Muñoz Renedo 1963: s. v. rabo de gato) - y llega a puntos del poniente almeriense, en la Sierra de Gádor, donde se distingue entre el rabogato ("S. foetens") y zabareña ("S. hirsuta" y "S. glacialis"); en Jaén vuelvo a encontrarlo con la var. cola de gato en la zona medio-oriental de la provincia - La Iruela (Cazorla) (Blancoana 9 -1992- 56)-, rabogato es el término conocido en Villanueva del Arzobispo y Cuatros Villas para "Phlomis lychnitis" (Blancoana, 11 -1994- 78); y rabo de gato lo aporta Espantaleón (1947: 36) en Jaén, sin localización, para el "Trifolium cherleri L.». Esta denominación conecta, por un lado, la franja almeriense con Murcia (Obón de Castro 1991: 37 y 109; Gómez Ortín 1991: s. v.; Morales 1996: 127), y,

48 Este término no es desconocido en el Levante y Oriente peninsular, en Mazarrón (Murcia) se encuentra zagareña (Obón de Castro 1991: 37), en Teruel zabareña, $\mathrm{e}$, incluso, está documentado en la Comunidad Valenciana, donde rabogato y vars. tienen su dominio principal (Morales 1996: 127).

4 En Sierra Cabrera también se le conoce como chichefraile, lo mismo que para la "S. ibenyzii" en Mazarrón (Murcia) (Cf. Obón de Castro 1991: 37). 
por otro, la jiennese con las sierras de Segura y Alcaraz y el Campo de Montiel en Albacete (Verde 1998: 283; Esteso 1992: 358) y con la Alcarria conquense (véase el mapa n. ${ }^{\circ}$ ), aunque aquí rabogato designa una planta de la familia de las carriáceas, "Eriathus ravennae" (Cf. Calero 1987: 199); continúa esta área léxica por la Comunidad valenciana, donde para distintas sideritas, junto a la forma castellanizada rabo de gato, aparecen rabo de gat ${ }^{50}, \mathrm{y}$, comparte con Cataluña, coa de gat y cúa de gat (Guillen García 1974: s. v.; Mulet 1987: 128; Morales 1996: 127); finalmente, rabogato llega al Alto Aragón (Villar Pérez 1987, 224; Morales, 1996, 127).

En conclusión, para distintas sideritas encontramos tres términos con sus correspondientes áreas: $\mathrm{El}$ orientalismo rabogato (rabo de gato), que se extiende por la comarca del noreste de Almería, y una pequeña zona del centro-este de Jaén - aunque aquí conviviendo con las otras denominaciones-; cuyo origen, como en los otros dos casos, debe a una metáfora, posiblemente motivada por los tallos que terminan en espigas que se asemejan al apéndice de este animal. El término zabareña, con distintas variantes, es el general en Andalucía, y de aquí se extiende a otras regiones españolas; para el étimo de esta voz, García Gómez (1977: 397) propone la raíz ár. $s f r$, que para las plantas tiene el valor 'de color amarillo', aunque no hay que descartar otro valor que el citado arabista da a esta raíz, el de 'vacío', porque, si bien algunas de estas especies tienen la inflorescencia amarilla, esta circunstancia no es una constante en el género, y sí lo es el vivir en lugares solitarios y apartados, como lo caracterizó Colmeiro (1885 III: $s . v$.) por ser "brava y montaraz" ${ }^{51}$. El último de los nombres recogidos, garranchuelo (garranchillo) para designar las sideritas, sólo lo he encontrado en Andalucía Oriental; es un derivado de garrancho (compuesto a partir de garra más gancho), que el DRAE, s. v., recoge con el valor 'la parte saliente o aguda del tronco o una rama de una planta'; en este caso - según creo- ha pasado a designar estas plantas por la forma de 'garra' que tiene uno de los dos labios del cáliz, como ya se ha dicho en la descripción.

50 El DCELLC: $s$. $v$. rabo, sostiene que rabo es un préstamo castellano en el valenciano; y que en esta variante del catalán se diferencia entre cúa, aplicada a los animales de cierta envergadura y con abundante pelo, y rabo para los pequeños animales y con apéndice más pelado; Cf. las plantas cúa de cavall y rabo de gat.

51 El DCECH: $s . v$. zahareño, da como étimo un derivado del ár. sajra 'roca', que se aplicó principalmente a las aves que se crían en peñas. 


\subsection{Estudio etnográfico}

En toda la zona estudiada se consideran las sideritas como plantas de efectos muy beneficiosos para la salud, aunque dos son las aplicaciones más usuales; en primer lugar, de forma general, para tratar las úlceras gástricas u otras molestias estomacales; en este caso se toma en ayunas, en general durante nueve días, una infusión de los tallos o inflorescencia de estas plantas. El otro remedio para el que se ha venido utilizando ha sido para desinfectar, curar y cicatrizar las heridas, y tratar las quemaduras, tanto de personas como de animales; para ello unas y otras se lavan con el agua obtenida de hervir sus tallos con las espigas. Por último, también se toma como analgésico (Cf. Blancoana, 9 -1992-, 51 y 56; González-Tejero 1989: s. v. “Sideritis"; Torres Montes 1994: 514) ${ }^{52}$. Otros usos locales son, en la Cuenca Media del Almanzora, para luchar contra los "golondrinos" (infarto glandular en el sobaco) para lo cual se aplica localmente, mezclada con tomillo; también en esta comarca, su infusión se usa contra resfriados, reúma y asma (potestativamente con tomillo, romero y olivarda); y con sal para realizar pediluvios contra las hinchazones de los pies (García Ramos 1987: s. v. rabogato). En la comarca de Nijar-Cabo de Gata se aplica a otros remedios, en tratamientos hepáticos, para lo que en la infusión se le añade a nuestra planta tomilllo y una cucharada de aceite; contra las afecciones oculares; como estimulante del apetito; depurativo sanguíneo -mezclando sus tallos floridos con cantueso y con unas cucharadas de miel-; contra el dolor de muelas; y como tonificante en los procesos de astenia, para lo cual se suele mezclar con cantueso y tomillo (véase Martínez Lirola 1997: 273-274).

52 La tradición de curar las heridas es muy antigua; ya el Dr. Laguna nos explica por qué estas plantas toman el nombre de sideritas, ya que en griego "sideros significa el hierro [...], porque esta planta suelda las heridas hechas con hierro". Dioscórides distinguía tres especies, aunque todas aplicadas sus hojas een forma de emplasto, sueldan las frescas heridas y hazen que no se apostemen" (Laguna 1968: 395-396). Font Quer (1989: 661), además de la aplicación como vulneraria, señala su uso en la costa mediterránea como digestiva, para ello se preparan en forma de tisana sus flores. En la actualidad su uso para tratar problemas estomacales y como vulneraria está muy generalizado; en Murcia se emplea como digestiva, a veces acompañada de una copa de anís (Obón de Castro 1991: 37 y 109); en Albacete para curar las afecciones estomacales, las úlceras, como digestiva, incluso como aperitivo; y para desinfectar las heridas en las Sierras de Segura y Alcaraz (Verde 1998: 193-196) y en el Campo de Montiel (Esteso 1992: 358); en Castellón para combatir los problemas digestivos, además como antiflamatoria, vulneraria, diurética y oftamológica (Mulet 1987: 128); en el Alto Aragón la "S. hirsuta" es utilizada como desinfectante y digestiva (Villar Pérez 1987: 224), y, por último, como antirreumática, en Málaga (Laza Palacios 1952: 210). 


\section{TAPANERA MATAPANERA (Capparis spinosa L.)}

8.1. Se trata de la planta de la fam. de las caparidáceas que en el español estándar recibe el nombre de alcaparra. Tiene sus ramas postradas, extendidas por el suelo, con hojas ovales de peciolo corto en cuya base se encuentran las espinas; posee grandes y vistosas flores con pétalos ovales de color blanco o rosado y numerosos estambres, por fruto unas bayas de color verde claro, también ovoides y unas semillas negras en forma de riñón. Es conocida y utilizada desde los griegos y romanos; crece espontáneamente en todo tipo de terrenos en el área mediterránea, aunque en la actualidad en zonas de Almería y Granada se ha cultivado para aprovechar el botón floral y su fruto.

\subsection{Estudio lingüístico}

El DRAE recoge para esta planta, además de alcaparra, las voces sinónimas, sin especificar zonas, alcaparrera, alcaparro y tápara; para Arag. da caparra; para Alb. y Murc. tápana; y tápena la hace exclusiva de esta última región. Sin embargo, estos datos, además de incompletos, no coinciden siempre con los que dispongo ${ }^{53}$, porque si la voz alcaparra es la más extendida en el dominio español para designar tanto la planta como el botón floral ${ }^{54}$; caparra aparece también en Andalucía (en Málaga, Granada y Almería; ALEA, II, m. 300) y en Murcia para designar su fruto (Obón de Castro 1991: 20); tápara sólo lo encuentro en el Alto Aragón (Ferrández 1993; Morales 1996: s. $v$. "Capparis spinosa"); y tápana y tápena; son orientalismos peninsulares de mayor extensión que la señalada por la Academia (véase el mapa n. ${ }^{\circ}$ 5); la primera voz se extiende desde el noreste de Almería hasta Murcia; la segunda aparece también en Almería y en una pequeña zona del noreste de Granada; aunque estas voces no designan la planta sino su botón floral o en algún caso su fruto, pues en toda esta zona — como en el dominio cat. y murc. - se distingue entre la

53 Sólo en Andalucía, las variantes no recogidas en el DRAE son numerosas: acaparra, alcaparronera, alcaparrón, caparrera, camparronera, chicorera, escaparrera, escaparronera, mata de alcaparrones, etc. (véase ALEA, II, m. 300; y Blancoana, 15 $-1998-6,45,63$ y 81).

54 Aunque hay autores que distinguen entre los dos términos, como Terreros (1771, Traducción al Espectáculo de la Naturaleza escritas en francés por el A. Pluche, IV, 43, apud DHLE: s. v. alcaparra) "Los alcaparros [...] que no son el fruto de la alcaparra o planta que las produce, sino los botones que [...] se abrirán en flores". 
mata: tapanera matapanera (fems.), el botón floral: tápena o tápana (fem.), y el fruto, como veremos a continuación ${ }^{55}$ (Cf. Sevilla 1990: ss. $v v$; García Soriano 1932: ss. vv.; ALEA, II, m. 300; Morales 1996: s. $v$. "Capparis spinosa"; Escrig 1871: s. v. tápera, taperera y taperot; DCELLC: s. $v$. tápera).

La isoglosa que divide la provincia de Almería en dos áreas léxicas desiguales se inicia, una vez más, desde el límite entre los municipios de Níjar y Carboneras en la costa ${ }^{56}$, pasa por el norte de la Sierra de los Filabres, y llega a una pequeña zona de la comarca bastetana, limítrofe con Almería, en la provincia de Granada; de manera que queda la zona occidental para alcaparra - alcaparrera, y la oriental para tapanera $\sim$ matapanera (encuentro, no obstante, un enclave en la Sierra de Gádor almeriense, término de Felix, donde se llama tápina a la inflorescencia, aunque la mata es alcaparra). Ya Rojas Clemente en sus obras en pre-

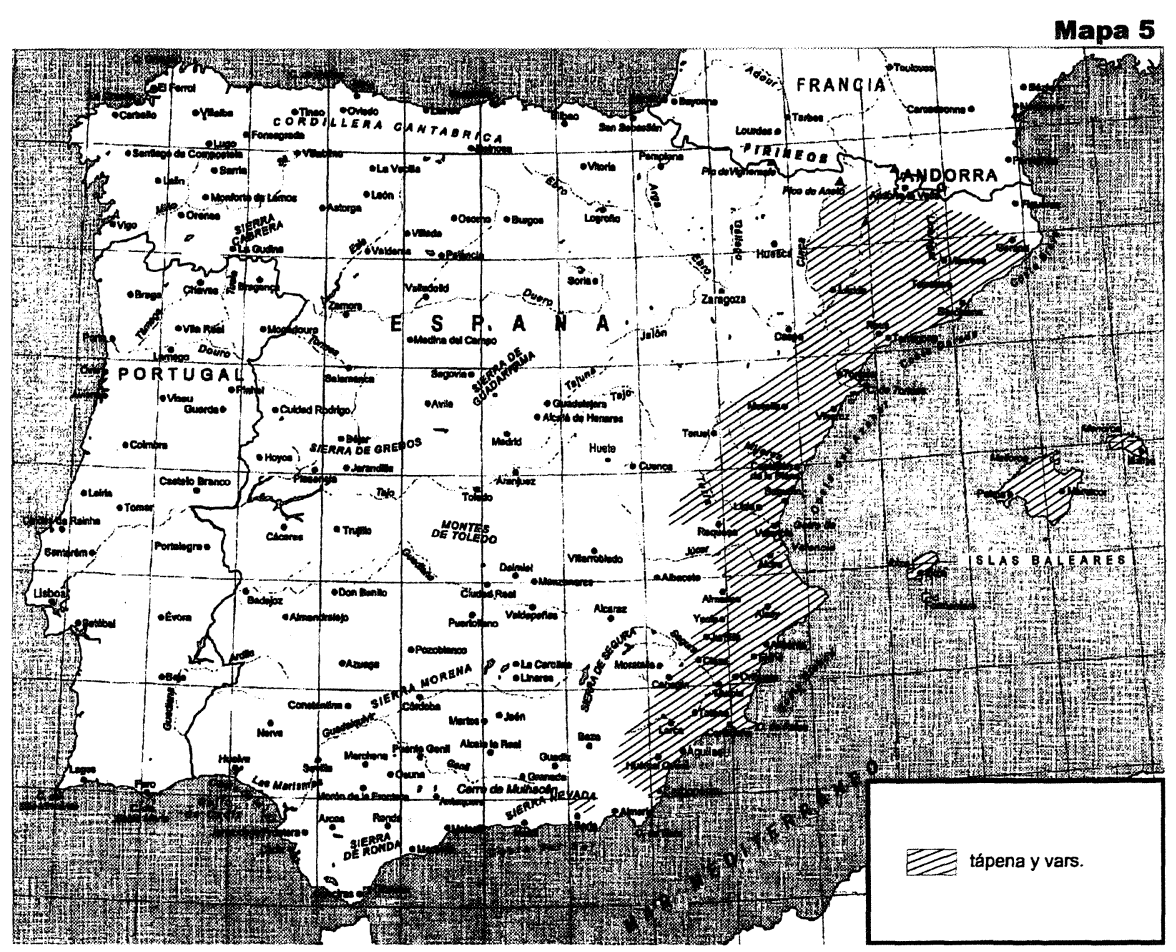

55 El DEA da entrada a las voces tápena, tapanera, como regionales, y las identifica con la planta.

56 Casado Fresnillo (1988: 264) siguiendo los datos del ALEA, traza esta línea más al oeste: desde San José (Níjar) a Alcóntar. 
paración (1805: 205; 1806: s. v.) documenta en Cantoria, Albox, Oria y Cuevas [de Almanzora] para la "Capparis spinosa" los nombres de tapanera para la mata, y tápena para la flor, tal y como hoy se conocen en toda esta comarca ${ }^{57}$. En Granada, Rojas Clemente (1806) incluye el término de Baza en la zona donde se dan las formas tapanera y tápena; si la información del citado botánico es cierta, desde principios del siglo XIX han ido ganando terreno las formas con [k-], pues sólo queda tápena en una franja en el límite con la provincia de Almería, que el ALEA, II, m. 300, documenta en Freila ${ }^{58}$; en el resto de esta provincia predominan los derivados de "alcaparra" (caparra, alcaparrera, escaparrera, escaparronera y alcaparronera, esta última es la forma dominante en el resto de Andalucía). En Jaén sólo se conocen estas últimas formas, además de algunas variantes nuevas: alcaparro, caparrera y arcaparrón, mata de acaparrones, alcaparronera (Cf. ALEA, II, m. 300; Espantaleón 1947: 28; Blancoana, 15 -1998- 63 у 81).

La variante matapanera sólo la he recogido en la provincia de Almería, en Sorbas y en una franja entre los municipios de Carboneras y Lucainena de la Torres que linda con el término de Níjar; esta voz se ha producido por la aféresis de la primera sílaba de tapanera al ir precedida del mismo sonido en el sintagma mata tapanera, a ello habrá influido la etimología popular. Alcalá Venceslada (1980) recoge la voz taparote 'alcaparrón' en Almería, que no he encontrado en mis encuestas, y que el DRAE hace extensiva a la provincia de Murcia.

El botón floral, en la zona andaluza de tapanera matapanera, es tápena o tápana; aunque en el ALEA no se pregunta por él, en algún caso se da su nombre confundido con la planta o con el fruto. Por lo que respecta al fruto, 'el alcaparrón', la forma mayoritaria en Andalucía es caparrón, no obstante en Granada es escaparrón, y en esta provincia, junto a la de Almería, aparece una serie de denominaciones en las comarcas orientales, que metafóricamente hace alusión a su forma: limoncillo, meloncico o meloncillo, pelotilla, etc., y sólo en Almería se documenta pelota, calabaza, pepino de tapanera, pera de tapanera, o pera de tápana (también encuentro tápana por confusión con el botón floral), que en la zona donde se recolecta, como ocurre como el botón de la flor, se clasifica en tres tamaños: fino, menudo y gordo.

57 En el ALEA, II, m. 300 ("Capparis spinosa"), en Almería, aparecen tapanera en Vélez Rubio, Contador, Oria, Perulera, Pulpí, Lúcar, Cantoria, Vera, Lubrín y Carboneras; al 'alcaparrón' se le llama tápana en Vera, Palomares-Villaricos y Gafarillos y la var. tápena en Oria, y Pulpí.

58 Blanca (1991: s. $v$. "Capparis spinosa") para la Sierra y Comarca de Baza recoge alcaparrera para la planta, alcaparra para la flor, y alcaparrón para el fruto. 
La forma latina CAPPARIS ha dado en la Península, como venimos señalando, distintas variantes, junto a alcaparra en castellano - sin el artículo, caparra, en portugués, en rioj. nav. y arag.-, ya encontramos en hablas mozárabes y hoy en una extensa zona, desde el sureste y el oriente peninsular, las variantes con t- inicial. Las formas documentadas en dialectos mozárabes son táparex, en Ibn Buclarix, tábara, taparayru ela y tapareruwela, docs. en el Glosario del Botánico Anónimo sevillano de h. 1100 (Cf. Galmés de Fuentes 1983: 36, 58-9), que con distintas modificaciones, han llegado hasta nuestros días en el área que, desde el noreste de Almería y Granada, se extiende por Murcia y parte del sur de Albacete, la Comunidad valenciana, llega a Cataluña y una franja de Aragón ${ }^{59}$; incluso estas formas con $t$ - transcienden el dominio hispánico, pues están presentes en hablas occitanas y del norte de Italia (véase DCELLC: $s . v$. tápera).

El paso de $k$ - a $t$ - (de CAPPARIS > tápera) lo explican CorominasPascual (DCECH: s. v alcaparra) por la contaminación de tapia, por etimología popular, ya que la alcaparra "se cría entre paredes viejas y cantos" $^{60}$. No creo que sea un rasgo definitorio de esta planta el criarse en paredes o derrivos de construcciones, porque si es verdad que en alguna ocasión se la ve crecer entre ruinas, como otras plantas, mi experiencia y la de mis encuestados es que se cría en cualquier lugar del campo principalmente en lugares incultos, bordes de los caminos y talu-

59 En Cataluña, Comunidad valenciana y en las Baleares, la forma general para designar esta planta es taperera - en Baleares domina taparera para la mata, tápera para el botón y taperot para el fruto, 'el alcaparrón' (Cf. Escrig 1871: ss. vv.; Albertí 1987: ss. vv.; Morales 1996: s. v. "Capparis spinosan; DCELLC: s. v. tápera), Jovellanos recoge tápara en Mallorca en su Descripción del Castillo del Bellver, en Aragón, junto a la forma cat. tápera 'planta de la alcaparra' en la zona bajo-aragonesa (Andolz 1984: s. v.), están tápara, que designa tanto la planta como el fruto, y taparera (Borao 1908: s. v.; Andolz 1984: s. v.; Ferrández 1993: s. v. alcaparra; ALEARN, lám. 352, ad.); en Murcia la voz tápana (ya documentado desde el Diccionario de Autoridades) está hoy en desuso -según indica García Soriano (1932: s. v.) -, también, empleada en el sur de Albacete; la forma más extendida en Murcia para designar la planta es tapanera -y la var. tapenera-, y tápena se emplea para el botón floral, aunque el DRAE, como se ha dicho, recoge esta última voz, como propia de la región de Murcia para la planta. Hay que señalar, no obstante, que en el noroeste de esta provincia el término usado es alcaparra (Gómez Ortín 1991: s. v.).

60 Vuelve Corominas, en el DCELLC: $s$. $v$. tápera, a tratar por extenso el origen de la $t$ - en cat. y, aunque no descarta la posibilidad de que existiese un duplicado T/ $C$ en fecha prerromana, se inclina de forma más decidida por la contaminación de palabras que combinan $p$-, $t$ - PETRA, PARIETE, y especialmente TAPIA; y termina diciendo, "En conclusió la contaminació de tapia és la més persusiva. 
des ${ }^{61}$. Creo más verosímil que se trate de una variante mediterránea de esta voz que tuviese $t$ - inicial en lugar de $k$ - y que ya apareciera en latín; y de esta primitiva forma hoy quedarían restos en el litoral mediterráneo de la Península Ibérica, Francia e Italia.

\subsection{Estudio etnográfico}

El principal uso que hoy tiene esta planta es el de preparar sus botones florales y el fruto en salmuera para utilizarlos como aperitivo o en las ensaladas. En toda la región de estudio, al ser el clima y el terreno muy propicios para su desarrollo, es abundante y se ha llegado a cultivar en los últimos años en distintas localidades de la provincia de Almería (Sorbas, Cantoria, Albox, Partaloa, etc.) y de Granada (zonas de Baza y Benamaurel); es, por tanto, un medio de vida de muchas personas que la recolectan, clasifican en tres tamaños y la envasan para exportar (ya Laguna [1555] - 1969: 248 - nos da noticia de cómo se traían de Alejandría a Venecia las alcaparras y las portaban conservadas en salmuera). No obstante, hay que decir que en nuestra región su empleo comercial es relativamente reciente, comienza en la década de los años 50 y por iniciativa de comerciantes murcianos ${ }^{62}$.

El empleo en la medicina doméstica es, por el contrario, tradicional en las tres provincias andaluzas orientales. Uno de los usos más generalizados ha sido para combatir el dolor de muelas, para ello se hierve un trozo de raíz y con el decocto elaborado se hacen enjuagues de boca (lo mismo en Murcia, Obón de Castro 1991: 20); ya Dioscórides —según Laguna 1968: 248 - nos informaba que su raíz "mordida del diente enfermo le relaxa el dolor. También se usa para curar las heridas infectadas, en este caso las partes de la planta utilizadas son sus tallos y las hojas (en Mula - Murcia-, sin embargo, se emplea la raíz; Cf. Obón de Castro 1991: 20), que se hierven en agua, y se lava la zona afectada (uso que también recoge Dioscórides para curar "todas las llagas viejas"; Laguna 1968: 248-9). Se utiliza, además —según documenta Martínez Lirola (1997: 143)—

61 Al describir Alonso de Herrera (1515) esta planta (Agricultura, apud DHLE: $s$. $v$. alcaparra) dice que alas alcaparras son unas matas que se extienden mucho por el suelo"

62 En la región murciana es tradicional el uso de los botones florales, los frutos y los tallos de la alcaparra conservados en vinagre o encurtidos para aperitivo; una copla antigua dice: "En el campo hay una mata/ que echa tres frutos al año,/ tápenas y caparrones, siendo primero los tallos/" (Cf. Sevilla 1990: s. v. tapanera). 
para aliviar el dolor de los huesos y de las articulaciones, en este caso, se emplea, junto a la raíz de la alcaparra, la del granado (para el médico-botánico griego Dioscórides era suficiente la raíz de nuestra planta). Por último, otros usos, no documentados en tratados que no sean actuales, son para evitar la caída del pelo e, incluso, como crece-pelo en Cabo de Gata, Níjar y Carboneras (Almería); en este caso el decocto de la raíz es utilizado como loción para el cuero cabelludo (Martínez Lirola 1997: 143). En Granada, en el litoral y en la zona de Alhama, y en la provincia de Jaén, la raíz se ha utilizado como diurética (Serrano López-Hermoso: s. v. “Capparis spinosa L.”; Espantaleón 1947: 28) ${ }^{63}$.

\section{BIBLIOGRAFÍA CITADA}

ABAD Merino, M. 1998. "La expansión del murciano por el oriente del reino granadino", en C. García Turza, et al. Actas del IV Congreso Internacional de Historia de la Lengua Española: II, 403-412, Logroño: Univ. de la Rioja.

Alarcón, P. A. 1983. La Alpujarra. Sesenta leguas a caballo precedidas de seis en diligencia. Granada: Editoriales Andaluzas Unidas. Ed. facsímil de la publicada en Madrid en 1874.

AlBERTí, S. y E. HERNÁNDEZ RoIG. 1987. Diccionari castellá-catalá i catalá-castellá. Barcelona: Albertí.

AlCAlÁ Venceslada, A. 1980. Vocabulario andaluz. Madrid: Gredos, reimpresión de la ed. de 1954

ALEA: Alvar, M., con la colaboración de A. Llorente y G. Salvador. 1961-1972. Atlas Lingüistico y Etnográfico de Andalucía. Granada: CSIC.

ALEANR: Alvar, M., con la colaboración de A. LlORENTE, T. Buesa y E. ALVAR. 1977-1981. Atlas Lingüístico y Etnográfico de Aragón, Navarra y la Rioja. Madrid: CSIC.

ANDOLZ, R. 1984. Diccionario aragonés-español, español-aragonés. Zaragoza: Librería General.

Asín Palacios, M. (ed.) 1944. Glosario de voces romances registradas por un Botánico Anónimo Hispanomusulmán (ss. XI-XII). Madrid-Granada.

AUTORIDADES: RAE. 1984. Diccionario de la lengua castellana [1726-1739]. Ed. facsimilar. Madrid: Gredos.

BELlaKHDAR, J. 1978. Médicine traditionelle et toxicologie ouest-sabariennes. Contribution a l'étude de la pharmacopée marocaine. Rabat: Ed. Techniques Nord-africaines.

BlanCA, G. de la. 1991. Flora del Parque Natural de la Sierra de Baza. Granada: Servicio de Publicaciones de la Universidad de Granada.

BLANCOANA. 1983-1998: Revista de botánica del Colegio Universitario "Santo Reino" de Jaén, 1983-1993; desde 1994 de la Universidad de Jaén.

BORAO, J. 1908. Diccionario de voces aragonesas. Zaragoza: Diputación Provincial.

BOISSIER, E. 1839-1847. Voyage botanique dans le midi de l'Espagne pendent l'anné 1837. 2 vols. Paris.

63 En la región murciana también se ha utilizado en infusión para los padecimientos estomacales (Sevilla 1990: s. v.). 
CAlero LóPEz DE AYAla, L. 1987. Léxico alcarreño conquense. Aproximación al estudio etnográfico de la comarca. Cuenca: Diputación Provincial.

CASADO FRESNILlO, C. 1989. Almería y sus relaciones lingüísticas con el oriente peninsular y con Andalucía. Madrid: UNED.

CEBAllos JimÉnez, J. 1986. Diccionario ilustrado de los nombres vernáculos de las plantas de España, Madrid: ICONA.

Colmeiro, M. 1885-89. Enumeración y revisión de las plantas de la Península Hispano-lusitana e Islas Baleares, con la distribución geográfica de las especies y sus nombres vulgares. 5 vols. Madrid.

Covarrubias, S. 1943. Tesoro de la lengua castellana o española [1611]. Ed. por M. de Riquer, Barcelona.

DCECH: COROMINAS, J., con la colaboración de J. A. PASCuAL. 1980-92. Diccionario Crítico Etimológico Castellano e Hispánico. Madrid: Gredos.

DEA: Seco, M., O. ANDRÉs y J. RAMOS. 1999. Diccionario del Español Actual. Madrid: Aguilar.

DEClLC: CoRominas, J. 1980-91. Diccionari Etimològic i Complementari de la Llengua Catalana. Barcelona: Curiel.

DEEH: GARCíA DE DIEGO, V. 1954. Diccionario Español e Hispánico. Madrid: Saeta.

DHLE: REAL ACADEMIA ESPAÑola. 1960 y ss. Diccionario bistórico de la lengua española. Madrid: Espasa-Calpe.

DRAE: REAL ACADEMIA EsPAÑOla. 1992. Diccionario de la lengua española. Madrid: Espasa-Calpe.

ESCRIG, J. 1871. Diccionario valenciano-castellano. Valencia: Librería Pascual Aguilar.

ESPANTAleón, R. 1947. Plantas medicinales de la provincia de Jaén. Contribución al mapa de la provincia geobotánica de España. Jaén.

EsTESO, F. 1992. Vegetación y flora del Campo de Montiel. Interés farmacéutico. Albacete: Inst. de Est. Albaceteños. Diputación de Albacete.

FERRÁNDEZ, J. V. y J. M. SANZ. 1993. Las plantas en la medicina popular en la comarca de Monzón (Huesca). Huesca: Instituto de Estudios del Alto Aragón. Diputación de Huesca.

FONT QUER, P. 1989. Plantas medicinales. El Dioscórides renovado. Barcelona: Lábor.

GALMÉS DE FUENTES, A. 1983. Dialectología mozárabe. Madrid: Gredos.

García Cabañas, M. ${ }^{a}$ J. 1965. Vocabulario de la Alta Alpujarra. Madrid: CSIC, Anejos del BRAE. XIV.

GARCía GómEz, E. 1977. "Paremiología y filología. Sobre "zahar" y "zahareño". $A l$ Alandalus 43: 391-408.

García Ramos, A. 1987. "Plantas que curan en Albox y valle de Almanzora", en: Albox. Feria de los Santos. Albox.

García Rollán, M. 1986. Plantas mortales en España. Madrid: Ministerio de Agricultura, Pesca y Alimentación.

- 1985. Claves de la flora de España (Península y Baleares). Madrid: Mundi-Prensa.

GARCía SORIANO, J. 1932. Vocabulario del dialecto murciano. Madrid: C. Bermejo.

GÓMEZ ORTín, F. 1991. Vocabulario del noroeste murciano. Contribución lexicográfica al español de Murcia. Murcia: Ed. Regional de Murcia.

Gómiz GARCía, F. 1989. "Apuntes para la divulgación de la geografía vegetal del término municipal de Chirivel». Revista velezana 8: 55-61.

GonzÁlez SAlas, M. 1994. Así hablamos (también). El español andaluz. Sevilla: Alfar. 
GONZÁLEZ-Tejero GARCíA, M. R. 1989. Investigaciones etnobotánicas en la provincia de Granada, Tesis doctoral, ed. en microfichas, Granada: Universidad de Granada.

GrierA, A. 1935-47. Tresor de la Llengua de les Tradicions $i$ de la cultura de Catalunya. 14 vols. Barcelona.

Guillén García, J. 1974. El habla de Oribuela. Alicante: Instituto de Estudios Alicantinos. Diputación de Alicante.

Laguna, A. 1968. Pedacio Dioscórides Anazarbeo [1555]. 2 vols. Madrid: Instituto de España.

Lahora Cano, A. 1997. "Evolución del paisaje de Sierra Cabrera y su entorno". Axarquía 2: $110-117$

LaZA Palacios, M. 1952. "Brujería, curanderismo y botánica". Gibralfaro 2-3: 205-210.

LÓPEZ, T. 1986. Diccionario Geográfico de Andalucía. Almería. Ed. de C. Segura. Almería: Diputación Provincial.

LLORENTE MALDONADO, A. 1985. "Coincidencias léxicas entre Andalucía y el Valle del Ebro". AFA 36-37: 347-375.

MADOZ, P. 1845 y ss. Diccionario Geográfico-Estadístico e Histórico de España y sus posesiones de Ultramar. Madrid.

MARín CAlderón, G. et al. 1984. Aportaciones al estudio del catálogo florístico de malas bierbas que invaden las plantaciones de los cultivos subtropicales de la provincia de Granada. Granada: Universidad de Granada.

Martínez Almoyna, J. 1998. Diccionario de português espanbol. Porto: Porto Editora.

MARTíNEZ ÁlVAREZ DE SOTOMAYOR, J. M. 1973. Obras completas, Cuevas de Almanzora (Almería).

Martínez Ezquerro, A. M.a 1994. El léxico de la flora de Alfaro (La Rioja). Logroño: Instituto de Estudios Riojanos. Diputación de la Rioja.

MARTÍNEZ KleISER, L. 1982. El Refranero general ideológico español. Madrid: Ed. Hernando.

MARTÍNEZ LiROLA, M. J. et al. 1997. Investigaciones etnobotánicas en el Parque Natural de Cabo de Gata-Níjar (Almería). Almería: Sociedad Almeriense de Historia Natural.

MASIP SALVI, R. y J. F. MUÑOZ PÉREZ. 1998. "Árboles y arbustos autóctonos de Vera". Axarquía 3: 136.

Medina Molero, A. y M. BARrera Ávila. 1980. Diccionario andaluz. Biográfico y terminológico. Sevilla: Biblioteca de Ediciones Andaluzas S. A.

MEDINA Y ESTÉVEZ, M. 1864. Monografía de las aguas y baños minero-medicinales de Lanjarón. Madrid.

MORALES, R. 1992, Nombres vulgares I. Archivos de Flora Ibérica, n. ${ }^{\circ}$, Madrid: CSIC. Real Jardin Botánico.

- et al. 1996. Nombres vulgares II. Archivos de Flora Ibérica, n. ${ }^{\circ}$ 7. Madrid: CSIC. Real Jardín Botánico.

Mulet PASCUAL, L. 1987. Etnobotánica farmacéutica de l'Alt Maestrat (Castellón). Castellón: Diputación Provincial.

- 1991. Estudio etnobotánico de la provincia de Castellón. Castellón: Diputación Provincial.

MUÑOZ RENEDO, C. 1963. "Estudio lexicográfico sobre el habla de la región de VélezRubio (Almería). RDTP, XIX: 393-414.

NAVARRO CARRASCO, A. I. 1986. "Orientalismos en andaluz". Español Actual 45: 347-375.

- 1988. "Voces murcianas y albaceteñas que reaparecen en el oriente andaluz", Espanol Actual 50: 61-72. 
NebrijA, A. 1979. Diccionario Latino-Español [1492]. Ed. a cargo de Colón - Soberanas. Valencia: Puvill-Editor.

- 1989. Vocabulario español-latino [1495?]. Ed. facsímil de la RAE.: 1951. Madrid: ArcoLibros.

OBÓN DE CASTRO, C. y D. RIVERA. 1991. Las plantas medicinales de nuestra región. Murcia: Consejería de Cultura.

PARDO AsSO, J. 1938. Nuevo diccionario etimológico aragonés. Zaragoza.

PARDO BERBEL, P. et al. 1987. Lengua y babla en nuestra comarca (Cuenca del Almanzora). Almería.

Peñarroja Torrejón, L. 1990. El mozárabe de Valencia. Madrid: Gredos.

Pizarro CAlles, A. S. a. Plantas medicinales en la provincia de Cuenca. Mérida: Instituto "El Brocense".

Plinio SECUNDI, C. 1877. "Naturalis Historiae", en Histoire naturelle de Pline, 2 vols. Ed. por M. Elittré. Paris.

RODRíguez Titos, J. s. a. El habla de los Montes Orientales, Granada: Ediciones Osuna.

Rojas Clemente, S. 1805. Historia Natural del Reino de Granada. t. V. Ms. conservado en el Jardín Botánico de Madrid.

- 1906 ( ¿ ?). Lista alfabética de nombres andaluzes de plantas. Ms. original de 31 pp., conservado en el Jardín Botánico de Madrid.

Rosal, F. del. 1992. Diccionario etimológico. Ed. facsimilar de E. Gómez Aguado. Madrid: CSIC.

Rueda CASinello, F. J. 1983. Diccionario almeriense. Almería: La Crónica.

SAGREDO, R. 1987. Flora de Almería. Plantas vasculares de la provincia de Almería. Almería: Instituto de Estudios Almerienses. Diputación Provincial.

SAlVADOR, G. 1953. "Aragonesismos en el andaluz oriental". AFA 5: 143-165.

- 1958. El babla de Cúllar-Baza. Contribución a la frontera del dialecto andaluz. Granada: PALA II [También en RFE, 41 (1957), 161-252; 42 (1958-59), 37-89; y RDTP, XIV (1958), 223-267].

- 1960. "Catalanismos en el habla de Cúllar-Baza", en Miscelánea Filológica dedicada a Mons. Griera: 335-342. San Cugat del Vallés-Barcelona: Instituto Internacional de Cultura Románica.

- SERrano López-Hermoso, R. 1932. "Flora medicinal de la provincia de Granada". Boletín de la Universidad de Granada 5: 441-487.

SEvilla, A. 1990. Vocabulario murciano [1." ed. 1919]. Murcia: Novograf.

SIMONET, F. 1967. Glosario de voces ibéricas - latinas usadas entre los mozárabes. [Ed. facsímil de la de 1888]. Madrid: Atlas.

TORO Y GISBERT, M. 1920. "Voces andaluzas (o usadas por autores andaluces que faltan en el DRAE)». Revue Hispanique 49: 313-647.

TORRES MONTES, F. 1989. "Orientalismos en el léxico de la albañilería en el Campo de Níjar", en J. Borrego Nieto et al. (eds.), Philologica. Homenaje a D. Antonio Llorente: vol. 1; 147-157. Salamanca: Universidad de Sa1amanca.

- 1993. La artesanía, las industrias domésticas y los oficios en el Campo de Níjar. Estudio lingüístico y etnográfico. Almería: Instituto de Estudios Almerienses. Diputación Provincial - Campus Universitario de Almería.

- 1994. "Usos y nombres vernáculos de algunas plantas espontáneas de Rodalquilar (Nijar)", en Psicología y Educación. Homenaje a la profesora Concha Zurita. Almería: Universidad de Almería - Diputación Provincial. 
- 1995. "Nombres de plantas espontáneas del litoral oriental de la provincia de Almería no recogidos en el DRAE», en J. de D. Luque Durán y A. Pamies (eds.), Primeras Jornadas sobre el estudio y enseñanza del léxico: 71-83. Granada: Ediciones Método.

VERDE, A. et al. 1998. Etnobotánica en las Sierras de Segura y Alcaraz. Albacete: Instituto de Estudios Albaceteños. Diputación Provincial.

VILlAR PÉRez et al. 1987. Plantas medicinales del Pirineo Aragonés y demás tierras oscenses. Huesca, Diputación Provincial.

ZAMORA VICENTE, A. 1943. "Notas para el estudio del habla albaceteña". RFE 27: 233-255. 